\title{
CONFIGURACIÓN TERRITORIAL DE LA PESCA COMERCIAL RIBEREÑA EN LA RESERVA DE LA BIOSFERA LOS PETENES, ESTADO DE CAMPECHE (MÉXICO)
}

\author{
José Manuel Crespo Guerrero \\ Universidad Nacional Autónoma de México \\ jcrespo@igg.unam.mx \\ ORCID iD: http://orcid.org/0000-0003-3728-9904 \\ Joaquín Daniel Nava Martínez \\ Centro de Investigación en Ciencias de Información Geoespacial, Consejo Nacional de Ciencia y Tecnología \\ jnava@centrogeo.edu.mx \\ ORCID iD: https://orcid.org/0000-0003-1253-3675
}

Recibido: 14-08-2019 Aceptado: 29-04-2020

Cómo citar este artículo/Citation: Crespo Guerrero, José Manuel y Nava Martínez, Joaquín Daniel (2020). Configuración Territorial de la pesca comercial ribereña en la Reserva de la Biosfera Los Petenes, Estado de Campeche (México). Estudios Geográficos, 81 (288), e040. https://doi.org/10.3989/estgeogr.202055.055

RESUMEN: La pesca a pequeña escala tiene una significativa perspectiva socioeconómica, ambiental y alimentaria; está considerada en la meta número 14 de la Agenda 2030 de Desarrollo Sostenible. En este marco global, resulta pertinente develar los rasgos territoriales de mencionada actividad en áreas protegidas que participan en el comercio internacional: tal es el caso de la Reserva de la Biosfera Los Petenes (282.858 ha). Para alcanzar dicho objetivo se reconocen: las infraestructuras, la organización de los pescadores, la explotación de los recursos y los flujos comerciales. La teoría de la Organización Espacial de la Economía fundamenta esta investigación que utiliza datos cuantitativos y cualitativos. Los resultados muestran un sector con buen acceso a los canales de comercialización nacional e internacional, pero con múltiples desajustes territoriales.

PALABRAS CLAVE: área natural protegida, pesca artesanal, geografía económica, economía azul, proceso económico

\section{TERRITORIAL ARRANGEMENT OF COMMERCIAL COASTAL FISHING IN THE LOS PETENES BIOSPHERE RESERVE, STATE OF CAMPECHE (MEXICO)}

\begin{abstract}
Small-scale fishing is a significant activity from a socioeconomic, environmental and alimentary perspective; and is considered in the goal number 14 of the Agenda 2030 for Sustainable Development. In this global context, it is relevant to reveal its territorial traits in natural protected areas, which participate in international trade, as in the case of the Los Petenes Biosphere Reserve $(282,858 \mathrm{ha})$. In order to reach this objective, the following aspects are recognized: infrastructure, the organization of the fishermen, the use of the resources and the commercial flows. The investigation, which uses both qualitative and quantitative data, is substantiated by the theory on the spatial organization of the economy. The results show a sector with good access to national and international commercialization channels, but with multiple territorial imbalances.
\end{abstract}

KEYWORDS: natural protected areas, small-scale fishing, economic geography, blue economy, economic process

Copyright: @ 2020 CSIC. Este es un artículo de acceso abierto distribuido bajo los términos de la licencia de uso y distribución Creative Commons Reconocimiento 4.0 Internacional (CC BY 4.0). 


\section{INTRODUCCIÓN}

La Organización de las Naciones Unidas para la Alimentación y la Agricultura (FAO por su sigla en inglés) afirma que más de tres mil millones de personas encuentran su fuente principal de proteínas en los océanos (FAO, 8 de junio de 2017, § 2). Por lo que no es de extrañar que, en numerosas comunidades de carácter rural, la pesca a pequeña escala sea su sostén económico debido a los empleos que genera (FAO, 2014). Sin embargo, dicha actividad ha manifestado desajustes relacionados con la pobreza y la inadecuada gestión del sector, sobre todo en los países en vías de desarrollo y menos adelantados.

El futuro de la pesca a pequeña escala se ensombrece aún más si se considera la contaminación marina, concretamente la procedente de la tierra, los detritos marinos y la polución por nutrientes (ONU, 2018); sin olvidar la frecuente ausencia de ordenamiento territorial: habituales son los casos de tensiones y conflictos entre la pesca artesanal y otras actividades como la pesca de gran altura y su industria (Álvarez, Gajardo y Ther, 2016; Aquije y Ortiz 2017), la acuicultura (Mestre, Ortega, Musoles y Ramos, 2015), el turismo (Zucco y Tomás, 2004; Crespo y Rivera, 2017), la energía hidroeléctrica y las grandes propiedades destinadas a la agricultura de exportación y a la ganadería extensiva (Sepúlveda, 2015).

La FAO señala que, a nivel mundial, es necesario alcanzar un estado sostenible en la dinámica pesquera, a través del cumplimiento de la normatividad y el ordenamiento del sector (FAO, 2018). Para ello es vital dimensionar los elementos sociales, económicos y ambientales que confluyen en dicha actividad. Entre las 17 metas que conforman los Objetivos de Desarrollo Sostenible (ODS), la número 14 dicta 'Conservar y utilizar sosteniblemente los océanos, los mares y los recursos marinos para el desarrollo sostenible'; pero ¿cómo conseguirla sin conocer la estructura económica de la pesca en territorios con múltiples particularidades?

Los objetivos propuestos por las Naciones Unidas son deseables, pero alcanzarlos pasa por explorar tantos caminos como realidades pesqueras (Phillipson y Symes, 2015; Van de Walle, Gomes da Silva, O'Hara y Soto, 2015; Felicidades y Piñeiro, 2018; Moreno, 2019). En este sentido, los Estados Unidos Mexicanos son uno de los países con mayor diversidad biológica del mundo, tanto por el alto número de especies que acogen, como por su diversidad biológica, genética y ecosistémica. Además, es reconocido por su heterogeneidad cultural, étnica y lingüística a nivel internacional. Todo ello da lugar a prácticas económicas contrastantes, incluso en una misma actividad. Por consiguiente, es fundamental reconocer las complejidades que presenta cada escenario vertebrado por el sector pesquero a pequeña escala; lo que contribuirá a entender las múltiples respuestas ofrecidas por realidades políticas, económicas y sociales concretas.

En el contexto global, los Estados Unidos Mexicanos tienen un gran potencial pesquero pues cuentan con $15.069 \mathrm{~km}$ de línea de $\operatorname{costa}^{1}$ que los posicionan como el tercer país con mayor longitud de litoral en el continente americano tras Canadá y los Estados Unidos (EE.UU.); tienen más de 3.000 .000 de $\mathrm{km}^{2}$ de territorio marino bajo jurisdicción nacional, poseen 76.306 embarcaciones pesqueras -siendo el $97 \%$ de pesca ribereña- y poco más de 300.000 trabajadores se dedican a la captura y la acuicultura (INEGI, 2017a; CONAPESCA, 2017).

México ocupaba en 2017 el puesto 17 en producción pesquera mundial en peso vivo desembarcado con 2.007.732 t -encabezaban la lista China (81.529.000 t), Indonesia (23.200.000 t) e India (10.785.000 t)-; exportaba por un valor de $\$ 1.265 .747 .000$ USD e importaba por \$1.219.484.000 USD, situándose en torno al trigésimo lugar por el valor de su participación en el mercado internacional, por tanto, en una posición intermedia (CONAPESCA, 2017). A estas cifras que resaltan el papel socioeconómico de la pesca, deben incorporarse los $694.591,82 \mathrm{~km}^{2}$ marinos (superficie parecida a la de Birmania) emplazadas en áreas naturales protegidas (ANP), en consecuencia, con herramientas propias de manejo ambiental que complementan a las pesqueras (CONANP, 2018).

En este horizonte, el Estado de Campeche, situado al occidente de la península de Yucatán, cuenta con una amplia plataforma continental, rica en ecosistemas marinos como lagunas costeras, pastos marinos y petenes ${ }^{2}$. Ello favorece la biodiversidad marina y también crea la necesidad de protegerla. Las ANP tienen mencionada misión: más de siete de cada $10 \mathrm{~km}$ de línea de costa se encuentran bajo alguna figura de conservación de la naturaleza. Desde el punto de vista de la actividad pesquera, en 2017, Campeche se situó como la octava entidad mexicana tanto en volumen de captura (58.764 t) como en su valor (\$87.915.045 USD) (CONAPESCA, 2017).

Entre las ANP de tipo costero que permiten la actividad pesquera, se halla la Reserva de la Biósfera 
Los Petenes (RBLP): es el espacio protegido de mayor superficie marina del estado con 181.991 ha. A pesar de no disponer prácticamente de población en su interior, presenta una dinámica pesquera relevante para Campeche. En busca de especies de alto valor económico -esencialmente pulpo-, llegan al ANP pescadores desde los municipios de Calkiní, San Francisco de Campeche (a partir de ahora S. Fco. de Campeche) y Champotón.

A raíz de lo expuesto, cabe preguntarse ¿cuál es el alcance de la actividad pesquera comercial ribereña en la RBLP?, ¿qué estructura tiene el sector que opera habitualmente en sus aguas protegidas?, ¿están ofreciendo resultados las herramientas de manejo pesquero? Es vital apreciar el sector desde un enfoque territorial para encontrar respuestas a estas cuestiones e incluso aplicar políticas públicas más eficaces que rompan el círculo vicioso creado entre las carestías económicas de los pescadores y la creciente escasez de recursos marinos generada por la intensificación de capturas.

\section{ENFOQUE TEÓRICO}

La planificación del territorio puede apoyarse a la perfección en la teoría de la Organización Territorial que se interesa en la territorialidad del funcionamiento de las fuerzas económicas productivas. Esta teoría reafirma los vínculos entre la distribución de los recursos naturales y la localización de los centros de producción, distribución y consumo. Su aplicación permite buscar soluciones que disminuyan desequilibrios, desajustes y posibles episodios de tensiones y conflictos entre actividades económicas y/o dentro de una misma.

En los años 1920 se desarrolló la Nueva Geografía Socialista que concibió la teoría de la Organización Espacial incorporando el concepto de estructura. Este posicionamiento ha sido retomado por diversos autores de la escuela soviética de geografía (Saushkin, 1962; Palamarchuk, Privalovskaya, Gorlenko y Runova, 1976; Diyakonov, Gramoteyeva y Kalashnicova, 1976; Frolova, 2002), secundados por la escuela regional francesa (George, 1976) y la cuantitativa anglosajona (Abler, Adams y Gould, 1972); además de una corriente ecléctica que ha destacado en América Latina, en México particularmente (Kostrowicki, 1975; Coraggio, 1976; Sánchez, Mollinedo y Propin, 2012). De tal forma que el concepto ha ganado amplitud al demostrar que la organización del espacio puede o no ser voluntaria y depende estrechamente de las actividades que los individuos o grupos colectivos ejecuten en el territorio.

La Organización Espacial pretende encontrar un orden en los elementos constituyentes de una actividad económica generada a partir de un proceso histórico que constantemente modifica el espacio para bien de los intereses humanos. Dentro de este concepto ha de diferenciarse entre estructura y proceso territorial. La primera hace referencia a la configuración presente de una actividad económica considerando las relaciones entre los espacios de producción y consumo. El segundo representa la dimensión dinámica vinculada a esas estructuras en el tiempo. De este modo es posible acercarse a los factores de producción que aúnan los naturales con los humanos y los tecnológicos.

El territorio tiene un papel esencial pues en él se delimitan las formas de organización social, las estructuras físicas y funcionales de las actividades económicas llevadas a cabo (Hernández, 1995). En esta línea, la pesca, al ser una actividad económica, se integra en los estudios de la Organización Espacial; además, dispone de una dimensión sociocultural que se expresa de manera tangible en las diferentes modalidades de apropiación del espacio, evolucionando por medio de los procesos territoriales. Las nuevas necesidades humanas y los avances técnicos promueven modificaciones en la organización de la actividad y sus relaciones con el territorio. Al respecto, Le Bail (citado en Yurkievich y Sánchez, 2016) menciona que la pesca es una de las actividades más complejas del sector primario, pues en ella confluye una amplia gama de factores: ambientales, económicos, culturales, sociales y políticos, lo que implica un proceso territorial que continuamente se encuentra modificando los rasgos espaciales.

\section{MARCO CONCEPTUAL}

Los geógrafos Cóccaro, Le Bail, Gómez y Boetto (2000) afirman que es posible distinguir la actividad pesquera de acuerdo con: la zona de pesca (ribereña, de altura y de gran altura), la pesquería, la distribución estacional de la especie objetivo, los tipos de embarcaciones y artes de pesca requeridos para las capturas, así como las zonas jurídicas conformes a los intereses económicos o ambientales a normalizar. En México, la Ley General de Pesca y Acuacultura Sustentables (LGPAS) define la pesca como "el acto de 
extraer, capturar o recolectar, por cualquier método o procedimiento, especies biológicas o elementos biogénicos, cuyo medio de vida total, parcial o temporal, sea el agua" (DOF, 24 de abril de 2018, p. 5).

La pesca comercial es aquella en donde la captura y la extracción se efectúan para obtener beneficios económicos. Atendiendo a factores como la distancia a la línea de costa, la tecnificación del equipo, el tipo de embarcación y los artes utilizados, es posible dividir esta modalidad en: ribereña, de mediana altura y de altura. La primera se realiza con embarcaciones y artes poco tecnificados ya sea en aguas oceánicas a un límite de $3 \mathrm{mn}$ a partir de la línea de costa o en aguas continentales. Sin embargo, los avances tecnológicos unidos a los materiales de las embarcaciones, las características geomorfológicas de la plataforma continental, la localización de las especies objetivo, entre otros factores, han empujado a la administración responsable a simplificar la concepción de la pesca comercial ribereña, considerándola como la que se realiza en embarcaciones menores, esto es, en una "unidad de pesca con o sin motor fuera de borda y con eslora máxima total de 10,5 m; con o sin sistema de conservación de la captura a base de hielo y con una autonomía de 3 días como máximo" (DOF, 24 de abril de 2018, p. 4). En definitiva, el término "pesca comercial ribereña" forma parte de la denominada por la FAO "pesca de captura a pequeña escala", término que es diverso e incluye un gran número de modos de organización.

En México, contrario a lo que se pudiera esperar, aún son insuficientes las publicaciones que han abordado esta actividad económica desde un enfque territorial. Aunque es de reconocer que, desde el comienzo de la segunda década del siglo XXI, se constata un considerable aumento de investigaciones en forma de tesis, capítulos de libro y artículos de investigación (Gráfica 1). Quienes han trabajado el tema recientemente bajo el posicionamiento de la Organización Espacial de la Economía son: Villerías (2009) y Villerías y Sánchez (2010), quienes estudian la Costa Chica de Guerrero; Martínez (2014) se centra en la pesca continental en la presa Jalpan; Yurkievich y Sánchez (2016) analizan la pesca en el puerto de Guaymas; Crespo y Rivera (2017) investigan la actividad pesquera en el Parque Nacional Bahía de Loreto; Campos y Crespo (2018) revelan la organización espacial de la pesca en la laguna de Términos; Crespo y Jiménez $(2016,2017,2018)$ y Crespo, Jiménez y Nava (2019) siguen publicando estudios sobre la pesca ribereña practicada en las penínsulas de Baja California y de Yucatán.
GRÁFICA 1

PUBLICACIONES GEOGRÁFICAS EN MÉXICO SOBRE LA ACTIVIDAD ECONÓMICA PESQUERA (2008-2019)

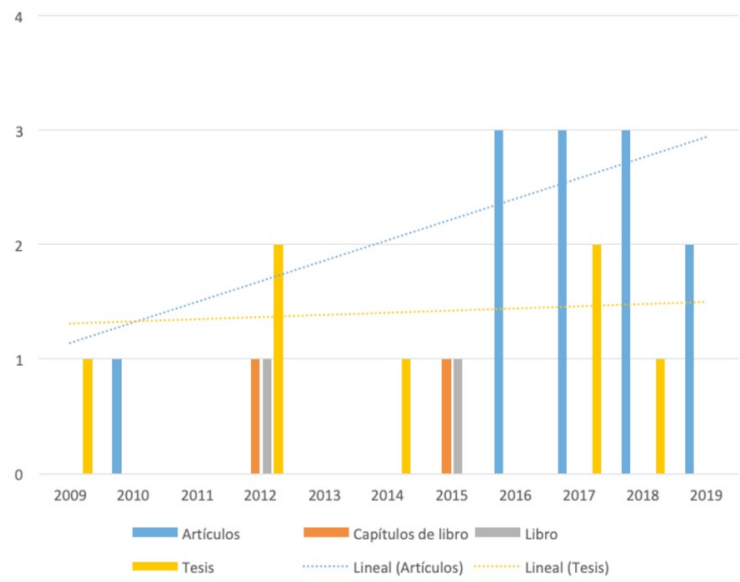

Fuente: datos procedentes de la revisión bibliográfica y hemerográfica. Elaboración propia.

\section{ESTRATEGIA METODOLÓGICA}

Con el fin de revelar la configuración territorial de la pesca comercial ribereña en la RBLP, se organizó el correspondiente trabajo de gabinete y de campo. En el primero, se procedió a la revisión bibliográfica de monografías y publicaciones periódicas propias de las ciencias ambientales, sociales y jurídicas. Los textos geográficos mostraron cómo la temática de estudio ha sido tratada desde la perspectiva territorial. Los legales esclarecieron la terminología empleada por los organismos oficiales mexicanos con competencias en materia pesquera y conservación de la naturaleza. También se consultaron documentos institucionales que arrojaron información socioeconómica y ambiental. El trabajo de campo constó de tres salidas: la primera tuvo lugar en marzo de 2016, se visitaron las localidades pesqueras de S. Fco. de Campeche e Isla Arena; la siguiente se emprendió en abril de 2017, se continuó trabajando en S. Fco. de Campeche y abarcó también Lerma; la tercera se llevó a cabo en octubre del mismo año y se concretó en Seybaplaya, Villa Madero, Ciudad Sol y Champotón (Mapa 1).

Se obtuvieron dos tipos de información primaria: por un lado, la cuantitativa ofrecida por entes oficiales como el Instituto Nacional de Estadística y Geografía (INEGI); la Secretaría de Agricultura, Ganadería, Desarrollo Rural, Pesca y Alimentación (SAGARPA); la 
Comisión Nacional de Áreas Naturales Protegidas (CONANP) y la Comisión Nacional de Pesca y Acuacultura (CONAPESCA); por otro lado, la información cualitativa, fruto de la aplicación de 86 cuestionarios semi-estructurados realizados a pescadores ribereños (Anexo) y 21 no estructurados o libres, dirigidos a responsables gubernamentales, presidentes de cooperativas y encargados de empresas privadas (Mapa 1).

Los cuestionarios semi-estructurados se establecieron en cuatro bloques temáticos y un anexo cartográfico: 'Aspectos socioeconómicos del pescador' (1); 'Aspectos técnicos: métodos, herramientas y tecnificación' (2); 'El arte de la pesca y los espacios de producción, almacenaje y comercialización' (3); 'La influencia del área natural protegida en la actividad pesquera' (4). El apartado cartográfico sirvió para que el entrevistado marcara los principales lugares de pesca y desembarco. 62 fueron las preguntas que organizaron los bloques, aportaron una información rica y útil que permitió conocer y comprender la organización de la pesca comercial ribereña.

MAPA 1

ITINERARIOS DE LAS SALIDAS DE CAMPO Y ENTREVISTAS REALIZADAS

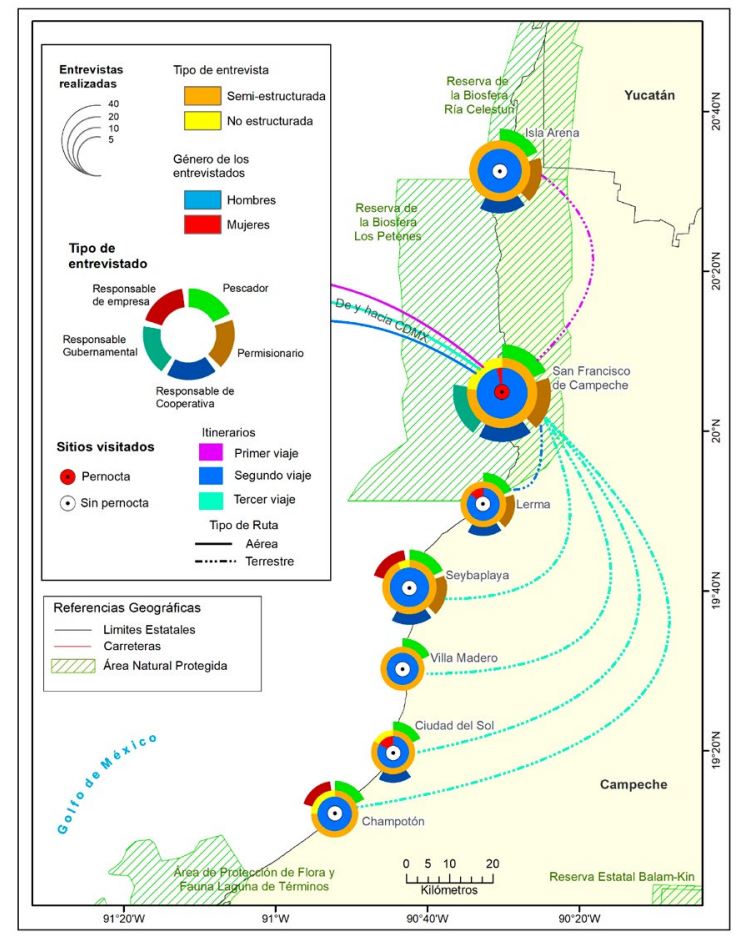

Fuente: datos procedentes de los trabajos de campo. Elaboración propia.
Un total de 107 entrevistas fueron realizadas en los espacios de trabajo (a pie de playa, muelles y bodegas) y residencia de las poblaciones de Isla Arena (22), S. Fco. de Campeche (38), Lerma (10), Seybaplaya (18), Villa Madero (6), Ciudad del Sol (6) y Champotón (8). Las entrevistas libres se produjeron en las oficinas de gobierno correspondientes a la CONAPESCA, la SEPESCA y la CONANP y en las instalaciones de empresas privadas como 'Sarricolea', 'Pescados y mariscos Orión’ y ‘Congeladora Salomón'. También se concertó una reunión con la dirección del frente común 'Apoyo al pescador Seybano' de la localidad de Seybaplaya. Los frentes comunes son asociaciones que velan por los intereses de los pescadores y de sus familias.

El análisis de la información cuantitativa permitió conocer las estadísticas pesqueras de la región y la generación de cartografía temática. La información cualitativa se trató de forma inductiva al compararla y codificarla, encontrando patrones y relaciones para conseguir un mayor conocimiento de la actividad económica pesquera (Strauss, Corbin y Zimmerman, 2002).

\section{RASGOS TERRITORIALES DE LA R.B.L.P.}

La RBLP, decretada el 24 de mayo de 1999, se emplaza en la península de Yucatán. Ésta separa el golfo de México del mar Caribe y alberga junto con sus mares adyacentes 50 ANP -en los estados de Campeche, Yucatán y Quintana Roo- que forman un conjunto ambiental de primera magnitud. Dicho grupo de espacios protegidos casi alcanza las 10.500 .000 de ha y funciona como un inmenso corredor ecológico marino-terrestre (Mapa 2).

La RBLP está localizada en la costa norte del Estado de Campeche, se extiende por cerca de $15 \mathrm{~km}$ de ancho en su porción terrestre, más $20 \mathrm{~km}$ en sus aguas protegidas, por $80 \mathrm{~km}$ de largo. Ocupa pues una superficie de 286.857 ha, de la que el $63,4 \%$ es marino (Mapa 3). La reserva abarca los municipios de Calkiní, Hecelchakán, Tenabo y Campeche. El ANP limita al norte con la Reserva de la Biosfera Ría Celestún; al oeste, en su porción marina, colinda con las aguas del golfo de México; al este avanza por los términos municipales de Calkiní, Hecelchakán y Tenabo; y al sur limita con la ciudad de S. Fco. de Campeche.

Las reservas de Los Petenes, Ría Celestún y El Palmar constituyen una ecorregión (la núm. 65 según la 
MAPA 2

ÁREAS NATURALES PROTEGIDAS DE LOS ESTADOS DE CAMPECHE, YUCATÁN Y QUINTANA ROO (2019)

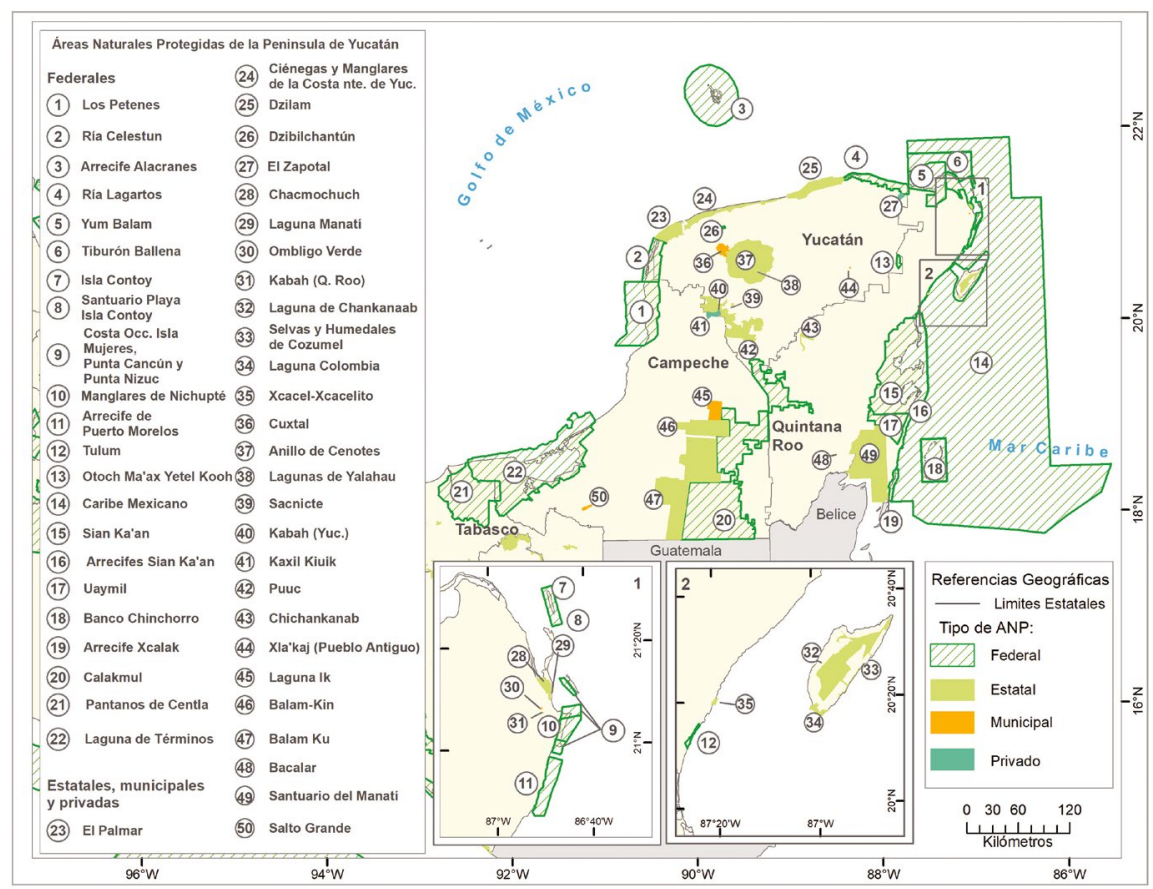

Fuente: CONANP (2019). Elaboración propia.

MAPA 3

LOCALIZACIÓN DE LA RESERVA DE LA BIÓSFERA LOS PETENES

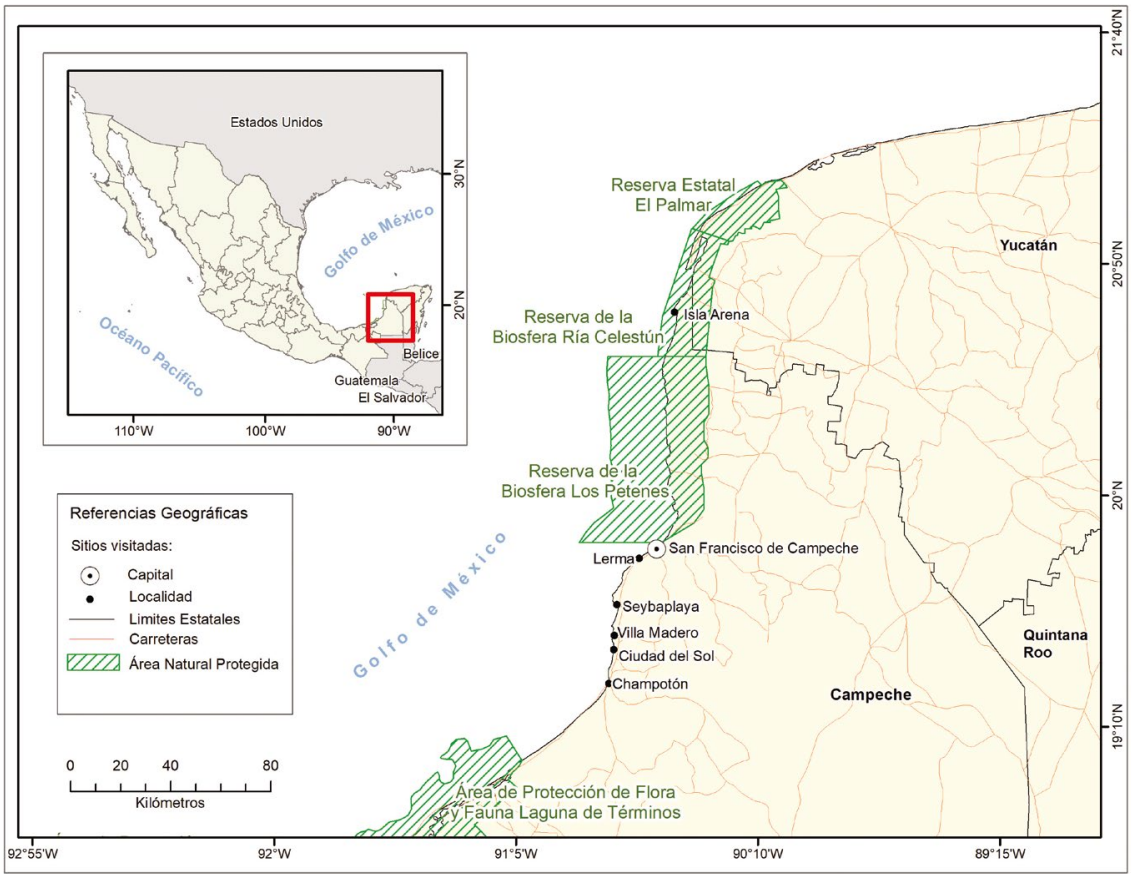

Fuente: CONANP (2019). Elaboración propia. 
ficha técnica de evaluación de los Sitios Prioritarios para la Conservación de los Ambientes Costeros y Oceánicos de México) distinguida por su alta biodiversidad. La RBLP registra al menos 1.151 especies de flora (46 endémicas de la península de Yucatán), 313 especies de aves (el $60 \%$ permanente y el $40 \%$ migratorio), 47 especies de mamíferos (16 bajo alguna categoría de riesgo), 47 especies de peces marinos, seis especies de peces de agua dulce y 21 especies de reptiles (CONANP, 2006). Las características naturales de la RBLP permiten la formación de ecosistemas favorables para las especies pesqueras, como los manglares y particularmente los petenes y los pastos marinos, que son los "de mayor extensión, tamaño y buen estado de conservación de todo el país" (CONANP, 2006, p. 13). Por lo que no es de extrañar que la RBLP esté incluida dentro de las regiones prioritarias de México en todas sus categorías: Región Prioritaria Terrestre (núm. 145: Petenes-Ría-Celestún), Región Marina Prioritaria (núm. 60: ChampotónEl Palmar), Región Hidrológica Prioritaria (núm. 102: Anillo de Cenotes) y Área Prioritaria para la Conservación de las Aves (clave 28: Los Petenes). Internacionalmente es reconocida como sitio Ramsar (núm. 1.354) desde el 2004 y el Fondo Mundial para la Naturaleza la identifica como la Eco-región número 50: 'Manglares de los Petenes'.

El ANP apenas registra asentamientos humanos: al sur de la reserva, el crecimiento urbano de S. Fco. de Campeche empieza a penetrar en el territorio protegido; por el oeste la invasión es aún más tímida, debido a la ampliación de pequeñas localidades rurales como es el caso de Kobén. Si bien es reducida la presencia de asentamientos humanos, existe una importante dinámica pesquera tanto en la porción marina de la reserva como en sus aguas adyacentes, pues la abundancia de fauna hidrobiológica y el alto valor económico del pulpo atraen a pescadores de localidades allende el polígono de la reserva. Sin olvidar, la amplia plataforma continental de la península que favorece la navegación de embarcaciones ribereñas hasta los $100 \mathrm{~km}$ mar adentro.

Como se mostrará, dos de las localidades analizadas concentran la mayor parte de la población de la zona de estudio. Una de ellas es S. Fco. de Campeche, capital y mayor urbe del estado, con más de 220.000 personas. A $8,5 \mathrm{~km}$ al sur, se halla Lerma que, según la encuesta intercensal 2015, posee 8.281 habitantes. En el municipio de Champotón, Seybaplaya, con cerca de 9.000 vecinos, es una localidad meramente pesquera pues cerca de la mitad de su población econó- micamente activa ha optado por la pesca. Sucede lo mismo con los pequeños núcleos de Villa Madero y Ciudad del Sol que cuentan respectivamente con una población de 3.954 y 628 habitantes; otro núcleo de población relevante es Champotón: esta pequeña ciudad de 30.881 habitantes es la más lejana a la RBLP, pero sobresale por su infraestructura pesquera. Si bien no menos importante, Isla Arena que es la única localidad situada al norte del ANP -se ubica en la colindante Reserva de la Biosfera Ría Celestún-, alberga 754 habitantes y sus pescadores suelen penetrar en la RBLP hasta Isla Jaina.

La figura Reserva de la Biósfera es una de las seis categorías federales de protección de la naturaleza en México ${ }^{3}$. El artículo 48 de la LGEEPA describe sus características:

Las reservas de la biosfera se constituirán en áreas biogeográficas relevantes a nivel nacional, representativas de uno o más ecosistemas no alterados significativamente por la acción del ser humano o que requieran ser preservados y restaurados, en los cuales habiten especies representativas de la biodiversidad nacional, incluyendo las consideradas endémicas, amenazadas o en peligro de extinción. (DOF, 5 de junio de 2018, p. 38)

Las reservas de la biosfera están sujetas a un marco normativo que mediante una sub-zonificación, define y delimita la forma de uso y/o explotación de los recursos naturales y de las actividades recreativas y/o turísticas. En las ANP mexicanas, las zonas núcleo son los polígonos más restrictivos, no se pueden realizar actividades extractivas, mientras que las zonas de amortiguamiento solo permiten actividades económicas compatibles con los objetivos de conservación.

El 23\% de la superficie de la RBLP es considerado zona núcleo, allí se aboga por la preservación de los ecosistemas a mediano y largo plazo; el restante $77 \%$ es zona de amortiguamiento, su función principal es orientar las actividades de aprovechamiento hacia la sostenibilidad. Se distinguen a su vez en esta área tres subzonas, la que interesa a la investigación es la denominada "aprovechamiento sustentable de los recursos naturales marina (sic)": en ella se realiza la actividad pesquera comercial ribereña y coincide con la distribución de los pastos marinos (Mapa 4). Desafortunadamente, el programa de manejo de la RBLP no se ha actualizado desde 2006, infringiendo la legislación ambiental de México que apunta que los programas de manejo de las ANP deben actualizarse al menos cada cinco años (DOF, 21 de mayo de 2014).

Las actividades económicas del Estado de Campeche se orientan esencialmente hacia la extracción 
MAPA 4

ZONIFICACIÓN DE LA RBLP

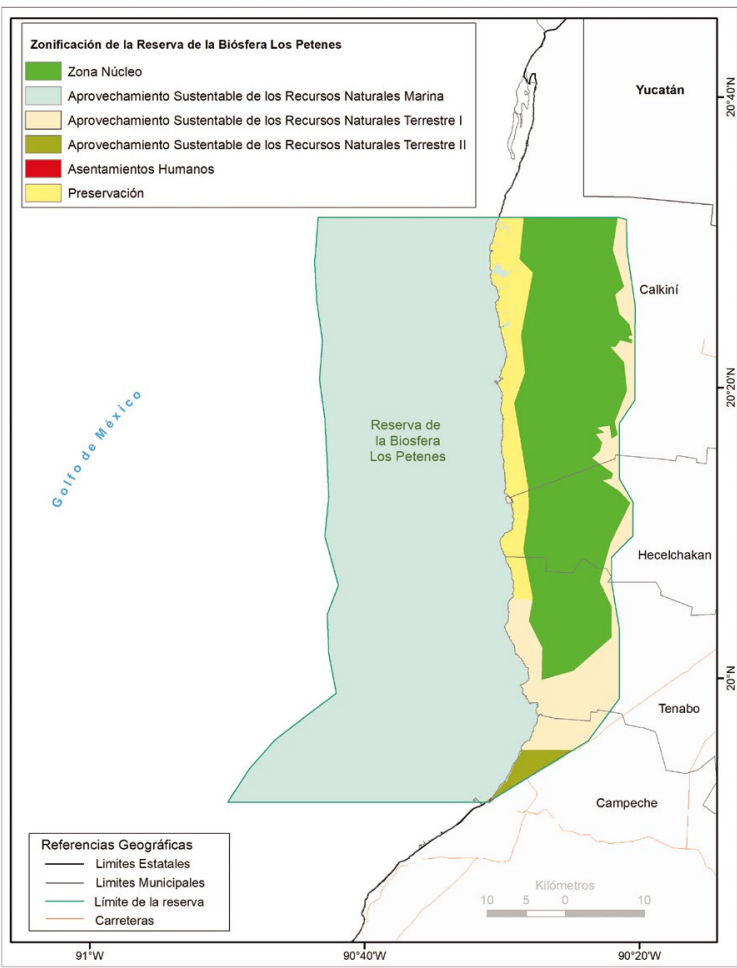

Fuente: CONANP (2006). Elaboración propia.

de hidrocarburos, cuya producción representa más de las tres cuartas partes del Producto Interno Bruto (PIB). Las actividades primarias como la ganadería, la agricultura, la explotación forestal y la pesca alcanzan en conjunto apenas el $1 \%$ del PIB estatal (INEGI, 2017a). La participación de la pesca en la riqueza del estado es mínima, pero ésta cobra relevancia territorial al constituir, como se justificará, el sostén económico para las localidades costeras menos pobladas de los municipios de estudio y complementar, tras la finalización de las actividades agrícolas, los ingresos de agricultores y trabajadores de ingenios (instalaciones para procesar la caña de azúcar).

Como se demostrará a continuación, en los últimos años, el aumento de la demanda internacional de productos del mar, su mayor circulación y el incremento de los precios, ha elevado la presión sobre dichos recursos. Esta situación representa un verdadero reto para la gestión y la normatividad de la RBLP, cuyo objetivo fundamental es buscar un equilibrio entre desarrollo social y protección de la naturaleza.

\section{INSTRUMENTOS LEGALES DE REGULACIÓN DE LA PESCA COMERCIAL EN A.N.P.}

A fin de acceder a los recursos hidrobiológicos, los pescadores en todo el territorio mexicano deben organizarse legalmente, bien bajo el sector privado bien dentro del sector social ${ }^{4}$. En el privado lo hacen en torno a dos figuras principales: la sociedad anónima (persona moral ${ }^{5}$ ), que se relaciona con organizaciones con fines lucrativos y los permisionarios (persona física) o pescadores que cuentan con permisos de pes$c a$, embarcaciones registradas y artes. El sector social engloba las sociedades cooperativas, id est organizaciones formadas por al menos cinco personas físicas bajo los principios de solidaridad, ayuda mutua y esfuerzo propio (DOF, 19 de enero de 2018). Los pescadores legales pueden acceder a los programas de apoyo que otorgan los gobiernos federal y estatal. Los más comunes son los de tipo económico: por temporada de veda y para renovación de embarcación y motor. Es de apuntar que también se conceden, aunque más escasamente, ayudas para la mejora de la infraestructura portuaria.

La LGPAS enuncia que, para proceder a la pesca comercial de los recursos de la flora y la fauna acuáticas en aguas de jurisdicción nacional, es de obligado cumplimiento disponer de una concesión o un permiso. La concesión es el título que se otorga a personas físicas o morales (sociedades), durante un tiempo definido de 5 a 20 años, con arreglo a informes de carácter técnico, social y económico de los solicitantes, así como la naturaleza de las actividades a emprender, las inversiones a realizar y los beneficios económicos a generar. El permiso también se da a personas físicas o morales para realizar actividades de aprovechamiento de los recursos acuáticos; se expide por embarcación, está sujeto a las temporadas de pesca o al plazo que determine el documento e indica la zona de captura, los equipos autorizados, los recursos pesqueros permitidos, las condiciones de operación y los artes de pesca.

La LGPAS es la base para la Carta Nacional Pesquera, documento redactado por el Instituto Nacional de la Pesca (INAPESCA), dependiente de la SAGARPA; sirve para regular el aprovechamiento de los recursos pesqueros y acuícolas en las aguas federales, incluyendo nociones para su conservación. La Carta Nacional Pesquera establece el esfuerzo pesquero, es decir: "número de embarcaciones, tonelaje de las mismas o frecuencia con la que se lanzan las artes de pesca" (DOF, 5 de julio de 2016, p. 6). También 
posee una detallada cartografía acompañada de datos sobre el diagnóstico, la evaluación de la actividad, la disponibilidad de los recursos y las acciones para la conservación, base para la autorización de los permisos y las concesiones.

La legislación ambiental y la pesquera condicionan las formas de realizar la actividad, en función de lo permitido y lo prohibido. De manera similar a otros aprovechamientos, el pesquero tiene que ser autorizado por la SAGARPA, apegada a la Ley General de Equilibrio Ecológico y la Protección del Ambiente (LGEEPA), de la que se desprende el Reglamento en materia de ANP (DOF, 21 de mayo de 2014) y todos los decretos, los programas de manejo, los avisos de veda y otros, contenidos en las disposiciones oficiales del país. Para pescar en las ANP, se requiere contar con autorizaciones que son expedidas por la Secretaría de Medio Ambiente y Recursos Naturales (SEMARNAT), tal como se indica en el Reglamento de la Ley del Equilibrio Ecológico y la Protección al Ambiente de Áreas Naturales Protegidas, artículo 88, fracción VI (DOF, 21 de mayo de 2014).

Todo lo explicado está en consonancia con lo que indica la Agenda 2030 para el Desarrollo Sostenible y de manera específica el ODS número 14 que llama a reglamentar la producción, evitar la sobreexplotación y las prácticas pesqueras destructivas, potenciar a los pescadores artesanales para alcanzar el desarrollo socioeconómico deseado, satisfaciendo las necesidades de empleo y acceso a la alimentación, sin descuidar el ambiente ni los recursos de la naturaleza (ONU, 2015).

\section{ORganización de LA ACTIVIDAD PESQUERA COMERCIAL RIBEREÑA DE LA R.B.L.P.}

Como se ha demostrado, las condiciones ambientales de la RBLP favorecen la presencia de especies haliéuticas; para entender el proceso económico de la actividad pesquera deben considerarse evidentemente los factores de tipo antrópico. Los elementos ambientales, legales, económicos, tecnológicos, entre otros, dan forma a la estructura territorial de la actividad económica pesquera comercial ribereña. Develarla supone comprenderla, paso sustancial para emprender cualquier política de intervención que tenga como fin su sostenibilidad evitando controversias. Para analizar la estructura de la actividad pesquera formal e informal, se considera el número y la procedencia de los pescadores, el alcance de la flota, la dimensión de las unidades económicas, las formas de acceso a los recursos, los artes de pesca, las capturas y el reparto de los beneficios, así como los flujos comerciales y sus mercados, sin descuidar, los desafíos de la pesca ribereña y el papel de las mujeres.

\section{a) La procedencia de los pescadores y los flujos internos}

Tal como se apuntó, en el interior de la RBLP, los núcleos rurales son escasos, poco habitados y no disponen de infraestructuras pesqueras. A las aguas protegidas de Los Petenes, llegan pescadores ribereños de los municipios de Calkiní (Isla Arena), Campeche (S. Fco. de Campeche y Lerma) y Champotón (Seybaplaya, Villa Madero, Ciudad del Sol y Champotón): sus localidades pesqueras poseen una población económicamente activa ocupada de casi 120.000 personas, el $5 \%$ se dedica a la pesca (INEGI, 2010). Esta cifra es igual a la que presenta la otra gran ANP marino-terrestre de Campeche, el Área de Proyección de Flora y Fauna Laguna de Términos (Campos y Crespo, 2018) aunque muy por debajo de la vecina Reserva de la Biosfera Ría Celestún: ocho de cada 10 trabajadores están vinculados a la actividad pesquera (Crespo y Jiménez, 2017).

La CONAPESCA posee oficinas en las localidades de Isla Arena, S. Fco. de Campeche, Seybaplaya y Champotón; según sus estimaciones, 6.104 pescadores ribereños regulares pescan potencialmente en la RBLP y en sus aguas aledañas, lo que representa el $61 \%$ del censo estatal de pescadores de bajura (Tabla 1 ). Las cifras incluyen a los eventuales que desde las zonas rurales se incorporan a la captura del pulpo -del 1 de agosto al 15 de diciembre- motivados por su abundancia y buen precio. El Secretario de Pesca de Campeche, José del Carmen Rodríguez Vera considera que más de 2.000 pescadores están en situación irregular, por lo que el número de personas que realizan la actividad en el estado, independientemente de su situación legal, supera el de 12.000 (Sánchez, 7 de junio de 2017). No es arriesgado afirmar que el dato de pescadores potenciales en la RBLP es mayor al brindado por las fuentes oficiales.

Al sur de la reserva, en su zona de influencia, se sitúan las localidades más pobladas, entre ellas la capital del estado que registra el mayor número de pescadores censados con 1.626; le siguen Seybaplaya (1.425) y Champotón (1.180). Si bien es cierto que el 
último núcleo se sitúa a unos $70 \mathrm{~km}$ de distancia por mar, su flota dispone de motores fueraborda potentes (superan normalmente los $75 \mathrm{hp}$ ) y de embarcaciones con la mayor capacidad de carga de la zona de estudio (Figura 1). En el censo de los pescadores de Champotón, se incluyen los de Ciudad del Sol y aquéllos eventuales que, en temporada de pulpo, se incorporan a la actividad desde zonas rurales como La Joya o La Noria.

Isla Arena es el único núcleo emplazado al norte de la RBLP, registra 568 pescadores, incluidos los de

TABLA 1

DATOS ECONÓMICOS POR GRUPO DE POBLACIÓN DE LAS LOCALIDADES DE INFLUENCIA PESQUERA EN LA RBLP Y RESTO DEL ESTADO DE CAMPECHE

\begin{tabular}{|c|c|c|c|c|}
\hline \multicolumn{5}{|c|}{ Localidades de influencia pesquera en la RBLP } \\
\hline Localidad & Población total & $\begin{array}{l}\text { Población económicamente } \\
\text { activa }\end{array}$ & $\begin{array}{l}\text { Población económicamente } \\
\text { activa ocupada }\end{array}$ & Pescadores \\
\hline Isla Arena & 754 & 242 & 242 & $568^{*}$ \\
\hline S. Fco. de Campeche & 220.389 & 98.325 & 95.818 & 1.626 \\
\hline Lerma & 8.281 & 3.649 & 3.533 & 484 \\
\hline Seybaplaya & 8.711 & 3.478 & 3.407 & 1.425 \\
\hline Villa Madero & 3.954 & 1.564 & 1.539 & 821 \\
\hline Champotón & 30.881 & 11.959 & 11.582 & 1.180 \\
\hline Subtotal & 272.970 & 119.217 & 116.121 & 6.104 \\
\hline \multicolumn{5}{|c|}{ Resto de localidades pesqueras del Estado de Campeche } \\
\hline Sabancuy & 7.286 & 2.983 & 2.961 & 734 \\
\hline Isla Aguada & 6.204 & 2.541 & 2.450 & 504 \\
\hline Cdad. Del Carmen & 169.466 & 73.255 & 70.898 & 970 \\
\hline Atasta & 2.535 & 632 & 537 & 570 \\
\hline Nuevo Campechito & 457 & 145 & 118 & $400^{*}$ \\
\hline Palizada & 3.089 & 1.249 & 1.197 & 718 \\
\hline Subtotal & 189.037 & 80.805 & 78.161 & 3.896 \\
\hline Total Estado de Campeche & 822.441 & 325.786 & 325.786 & $10.000 * *$ \\
\hline
\end{tabular}

* La población económicamente activa (INEGI, 2010) es inferior al número de pescadores (CONAPESCA, 2016) porque este dato contabiliza a los temporales que proceden de localidades aledañas del interior y refuerzan algunas campañas (población flotante estacional).

** En el total de pescadores no se contabilizan los 20 de escama dulce de Candelaria.

Fuente: INEGI (2010) y CONAPESCA-Campeche (2016). Elaboración propia.

FIGURA 1

EMBARCACIONES DE LAS LOCALIDADES DE CHAMPOTÓN (2017, IZQ.) E ISLA ARENA (2016, DCHA.)
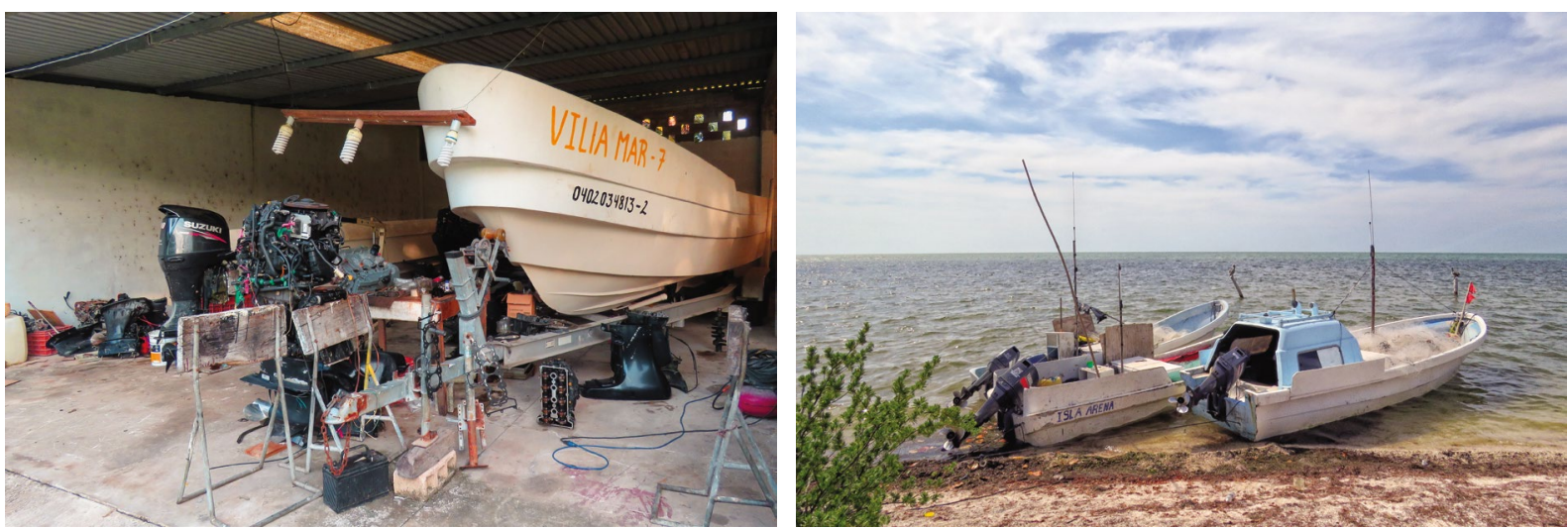

Fuente: Archivo de campo (2016/2017) 
tiempo parcial que provienen de los núcleos rurales del interior del municipio como Tankuché, San Nicolás, Santa Cruz y Santa María, para aunarse a la lucrativa captura del pulpo (Crespo y Jiménez, 2017). Los motores de las embarcaciones de Isla Arena no tienen un gran caballaje, raramente superan los $60 \mathrm{hp}$ y las lanchas, a diferencia de las de Champotón, no se han transformado para aumentar su capacidad (Figura 1). Isla Arena no dispone ni de gasolinera ni de fábrica de hielo, sus pescadores suelen trasladarse a la cercana localidad yucateca de Celestún -a unos $10 \mathrm{~km}$ por la línea de costa-para conseguir señalados insumos. Así se entiende por qué los pescadores isleños raramente rebasan la zona conocida como Isla Jaina, situada a poco más de $50 \mathrm{~km}$ al sur de su localidad en pleno corazón de la RBLP.

\section{b) La flota de bajura y la forma de las unidades económicas pesqueras}

El Registro Nacional Pesquero y Acuícola tiene inscritas en la zona de influencia del ANP, 1.706 embar- caciones menores, o sea, el $47 \%$ de la flota pesquera ribereña del estado (Tabla 2). Todas están fabricadas en fibra de vidrio, siendo la mayoría de marca IMEMSA (Industria Mexicana de Equipo Marino, S.A de C.V.) que a su vez es la distribuidora oficial en México de los motores japoneses Yamaha, justamente son los que abundan en el ANP.

Según estimaciones oficiales, las lanchas en situación ilegal, es decir, aquéllas que tienen permisos falsos y/o matrículas alteradas, rondan las 4.000 en el estado (Sánchez, 7 de junio de 2017). Es menester apuntar que en el Estado de Campeche se cuantifican 122 barcos de media y gran altura: Lerma registra 96 barcos camaroneros y dos de altura, más los 23 barcos camaroneros y uno de altura sitos en Ciudad del Carmen.

La CONAPESCA (2017) identifica 1.178 unidades económicas (UE) dedicadas a la pesca comercial ribereña en todo el estado: seis de cada 10 lo hacen en el sector social. Sólo se constatan ocho sociedades anónimas frente a las 472 personas físicas con permiso de pesca (denominadas en el argot como 'per-

TABLA 2

NÚMERO DE UNIDADES ECONÓMICAS DE RIBERA INSCRITAS EN EL REGISTRO NACIONAL PESQUERO Y ACUÍCOLA (2016) PARA LA ZONA DE INFLUENCIA DE LA RBLP Y RESTO DEL ESTADO DE CAMPECHE

\begin{tabular}{|c|c|c|c|c|c|}
\hline \multicolumn{6}{|c|}{ Localidades de influencia pesquera en la RBLP } \\
\hline Localidad & Sector social* & Personas físicas & Empresas privadas & Unidades Económicas & Embarcaciones menores \\
\hline Isla Arena & 10 & 126 & 0 & 136 & 286 \\
\hline S. Fco. de Campeche & 191 & 46 & 1 & 238 & 542 \\
\hline Lerma & - & - & - & - & 53 \\
\hline Seybaplaya & 256 & 14 & 0 & 270 & 475 \\
\hline Villa Madero & 1 & 0 & 0 & 1 & (incluidas en Champotón) \\
\hline Champotón & 22 & 165 & 1 & 188 & 350 \\
\hline Total & 480 & 351 & 2 & 833 & 1.706 \\
\hline \multicolumn{6}{|c|}{ Resto de localidades pesqueras del Estado de Campeche } \\
\hline Sabancuy & 36 & 65 & 3 & 104 & 367 \\
\hline Isla Aguada & 31 & 25 & 2 & 58 & 252 \\
\hline Cdad. del Carmen & 100 & 4 & 1 & 105 & 485 \\
\hline Atasta & 35 & 9 & 0 & 44 & 285 \\
\hline Nuevo Campechito & - & - & - & - & 200 \\
\hline Palizada & 15 & 19 & 0 & 34 & 359 \\
\hline Total & 217 & 122 & 6 & 345 & 1.948 \\
\hline Total Estado de Campeche & 697 & 473 & 8 & 1.178 & $3.654^{* *}$ \\
\hline
\end{tabular}

* Los Organismos del Sector Social de la Economía están reflejados en el artículo 25 de la Constitución Política Mexicana y desarrollados en la Ley de la Economía Social y Solidaria (Valenzuela 2012). En el caso de la pesca se trata de sociedades cooperativas, sociedades de producción rural, sociedades de solidaridad social y uniones de pescadores.

** En el total de unidades económicas y embarcaciones no se contabilizan los datos de Candelaria (dispone de una cooperativa con 10 embarcaciones). Fuente: CONAPESCA-Campeche (2017). Elaboración propia. 
misionarios') (Tabla 2). 833 UE pesqueras comerciales ribereñas se emplazan en la zona de influencia de la RBLP, lo que significa el $71 \%$ del censo estatal. A imagen de lo que ocurre en Campeche, el sector social del ANP está representado por seis de cada 10 UE; el resto corresponde prácticamente a permisionarios.

Respecto al tamaño que poseen las UE de pesca en el estado, el Directorio Estadístico Nacional de
Unidades Económicas (DENUE; INEGI, 2017b) confirma que el $61 \%$ tiene entre uno y 10 trabajadores, 10 puntos menos que en las localidades de influencia de la RBLP. Por ende, el tejido empresarial predominante de las UE es de tipo 'micro', teniendo un papel preponderante los permisionarios y las cooperativas pesqueras de corte familiar: las formadas por menos de 11 integrantes, unidos por lazos de parentesco o amistad (Mapa 5).

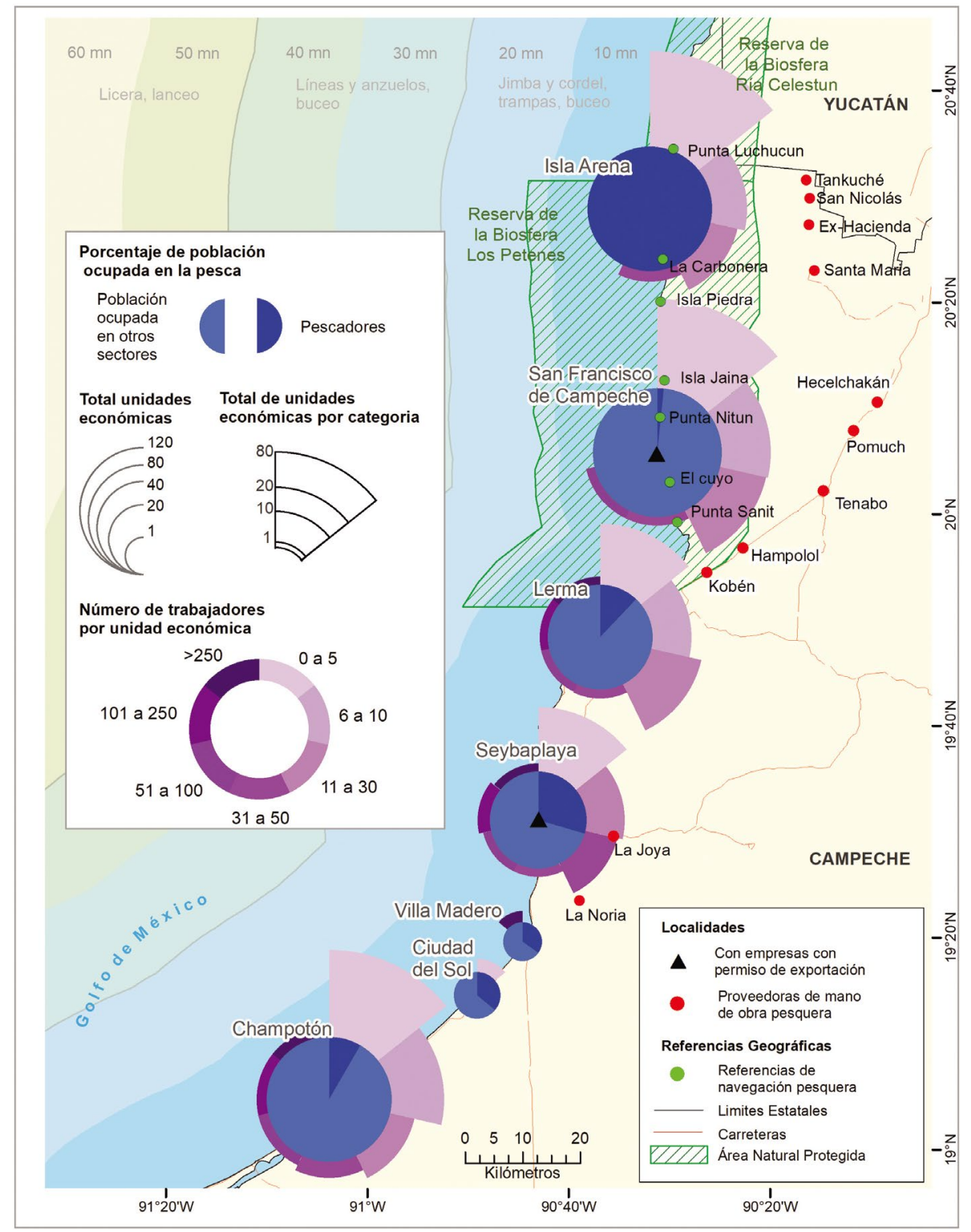

Fuente: INEGI (2017b) y CONAPESCA-Campeche (2017). Elaboración propia. 


\section{c) El acceso a los recursos, los artes de pesca y las capturas}

La RBLP no tiene concesiones pesqueras ni acuícolas, por consiguiente, la actividad legal se realiza por medio de permisos. El más común en la RBLP es el de escama marina (agrupa especies como jurel, boquinete, pargo, chac-chic, corvina, mero, rubia, canané, robalo...), seguido por los de pulpo (común y rojo o maya) y tiburón (sobre todo cazón). Atendiendo al valor comercial de las especies, se distinguen dos grupos: el formado por especies de importancia comercial y el de bajo valor económico (Tabla 3). En el primer grupo se posicionan el tiburón, el pulpo, el robalo y el caracol: un bajo volumen de captura puede asegurar un buen ingreso. El segundo lo aglutinan

TABLA 3

PRECIOS A PIE DE PLAYA Y EN BODEGA DE ALGUNOS PRODUCTOS PESQUEROS VENDIDOS EN SEYBAPLAYA (2016/2017)

\begin{tabular}{|c|c|c|}
\hline Producto pesquero & $\begin{array}{c}\text { A pie de playa } \\
\mathrm{MXN} / \mathrm{kg} \text { [\$USD/Kg] }\end{array}$ & $\begin{array}{c}\text { En bodega MXN/kg } \\
\text { [\$USD/kg] }\end{array}$ \\
\hline Pulpo & $90-100[4,76-5,29]$ & $105-110[5,55-5,82]$ \\
\hline Pulpo congelado & $90[4,76]$ & $110[5,82]$ \\
\hline \multirow{5}{*}{ Tiburón } & \multirow{5}{*}{$30-35[1,58-1,85]$} & Carne 150 [7.93] \\
\hline & & $\begin{array}{l}\text { Mandíbula } 250 \\
\text { (pequeña) [13.22] } \\
350 \text { (grande) } \\
{[18,51]}\end{array}$ \\
\hline & & $\begin{array}{l}\text { Piel } 500 \text { (por pieza) } \\
{[26,44]}\end{array}$ \\
\hline & & $\begin{array}{l}\text { Aleta } 2.000-2.300 \\
{[105,78-121,65]}\end{array}$ \\
\hline & & Cartílago 55 [2,91] \\
\hline Robalo & $100[5,29]$ & $120-125[6,34-6,61]$ \\
\hline Caracol & $50-55[2,64-2,91]$ & $62-80[3,28-4,23]$ \\
\hline Manta & $15[0,79]$ & $50[2,64]$ \\
\hline Cojinete & $50[2,64]$ & $70[3,70]$ \\
\hline Pargo & $50[2,64]$ & $70[3,70]$ \\
\hline Sierra & $35[1,85]$ & $45-50[2,38-2,64]$ \\
\hline Bagre & $20[1,06]$ & $30[1,58]$ \\
\hline Carito & $30[1,58]$ & $35-40[1,85-2,11]$ \\
\hline Jurel & $08[0,42]$ & $11[0,58]$ \\
\hline Cojinúa & $08[0,42]$ & $11[0,58]$ \\
\hline Lisa & $08[0,42]$ & $11[0,58]$ \\
\hline Bonito & $07[0,37]$ & $09[0,47]$ \\
\hline
\end{tabular}

Fuente: trabajo de campo temporadas (2016/2017). Elaboración propia. esencialmente las especies de escama marina. Aquí los pescadores buscan capturar importantes volúmenes para obtener un ingreso apropiado.

En el litoral septentrional del estado, el pulpo se ha convertido en la especie objetivo. Desde 2009, la demanda continuada de los mercados internacionales -europeos y asiáticos- ha mantenido el precio en torno a los $\$ 100 \mathrm{MXN} / \mathrm{kg}\left(\$ 5,29\right.$ USD para $\left.2017^{6}\right)$ aunque puntualmente ha descendido a los $\$ 60 \mathrm{MXN} /$ $\mathrm{kg}(\$ 3,17$ USD), en todo caso, muy por encima del precio anterior a 1996 (año en el que se produjo la primera internacionalización del producto) cuando costaba $\$ 7 \mathrm{MXN} / \mathrm{kg}(\$ 0,92 \mathrm{USD})$. Como resultado de este proceso, se ha invertido en infraestructuras $y$ capacitación en el manejo para cumplir con la normativa de higiene en el procesamiento del pulpo y así mantener las exportaciones y los buenos precios (Crespo y Jiménez, 2017).

Los artes legales se señalan en los permisos de pesca, los cuales se emiten de acuerdo con la Carta Nacional Pesquera y en este caso, también en consonacia con el Programa de Manejo de la RBLP. EI método legal para la captura del pulpo en el Estado de Campeche es con jimba y cordel. La jimba (Rhipidocladum pittieri) es una especie de bambú nativo que alcanza hasta los $12 \mathrm{~m}$ de longitud (los pescadores la adquieren a un precio cercano a los $\$ 100 \mathrm{MXN}$ [\$5,29 USD]). A la jimba se le ata un largo tramo de cordel con varias líneas llamadas pulperas, en cuyos extremos cuelga un anzuelo con carnada que normalmente es cangrejo maxquil (Stenorhynchus seticornis) y así, la embarcación permanecerá a la deriva durante unas horas: esta técnica es conocida como gareteo. A veces, las lanchas se acompañan de otras más pequeñas denominadas alijos (de no más de $2 \mathrm{~m}$ de eslora) que reproducen el arte.

Además de la jimba y el cordel, en las aguas adyacentes de la RBLP, se utilizan otros instrumentos legales como las redes que sirven para cercar los cardúmenes. El lanceo es el método para la captura de la corvina (utiliza paños de red) y la línea de red (ésta se suele extender por un $\mathrm{km}$ ) que se complementa con el buceo a pulmón para la pesca del boquinete. Otro tipo de arte legal es el uso de trampas que permiten la entrada, pero no la salida, de especies como el cangrejo; se utiliza un cebo para atraerlas. También es común el uso de palangres, conjunto de anzuelos para la pesca de escama. Los artes legales en la RBLP tienden a ser de carácter tradicional, son más adecuados para mantener las tasas de reproducción natural (Figura 2). 
FIGURA 2

ARTES DE PESCA LEGALES: JIMBA Y CORDEL (IMAGEN SUPERIOR IZQ.); REDES DE LUZ DE MAYA PERMITIDA

(IMAGEN SUPERIOR DCHA.); TRAMPAS (IMAGEN INFERIOR IZQ.); Y PALANGRES (IMAGEN INFERIOR DCHA.)
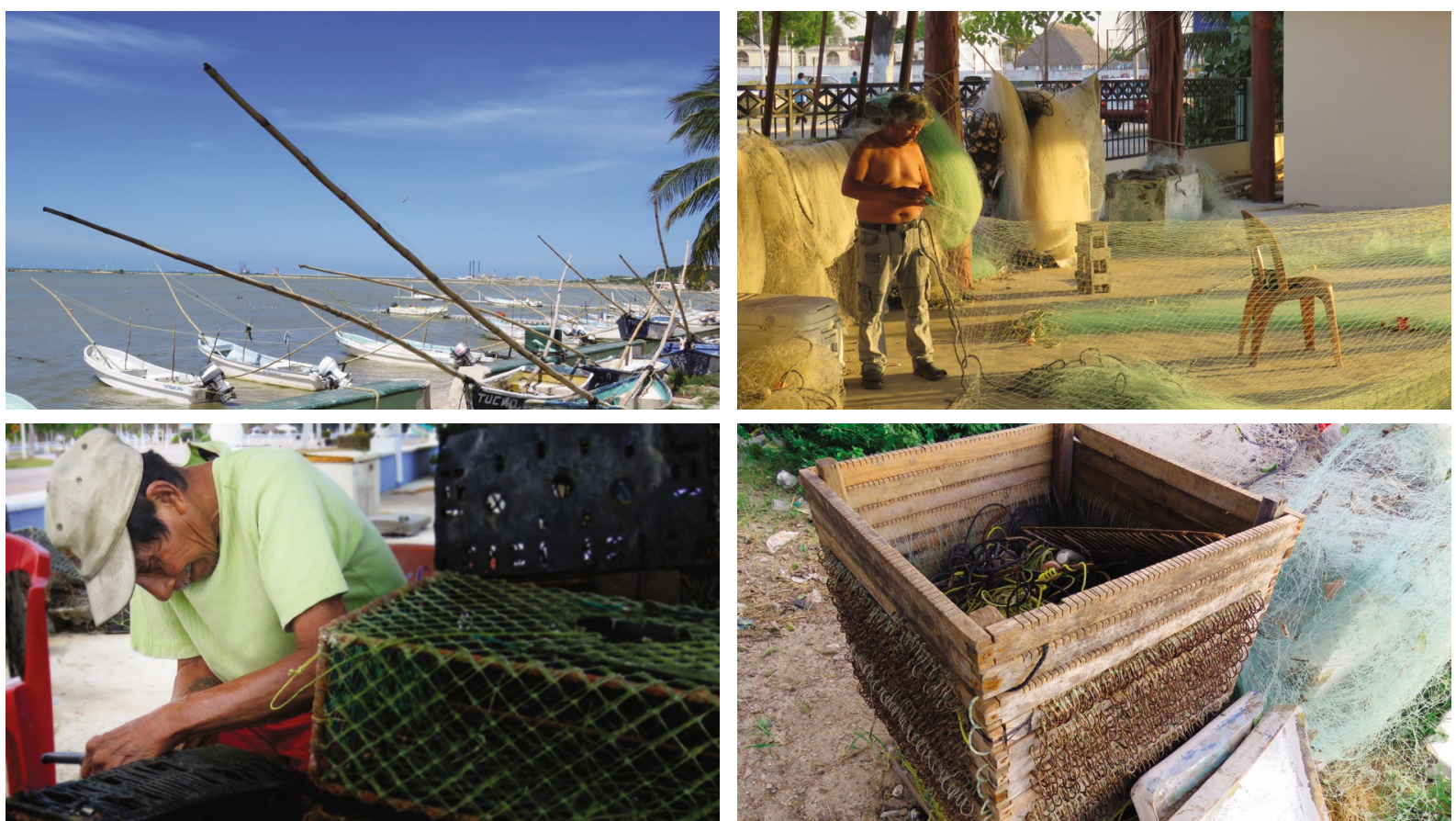

Fuente: Archivo de campo (2017).

FIGURA 3

ARTES DE PESCA ILEGALES Y ALEGALES (A LA IZQ. BOVEDILLAS PARA SER GEORREFERENCIADAS EN EL MAR; A LA DCHA. LÍNEA DE BOTES PARA LA PESCA DEL PULPO)
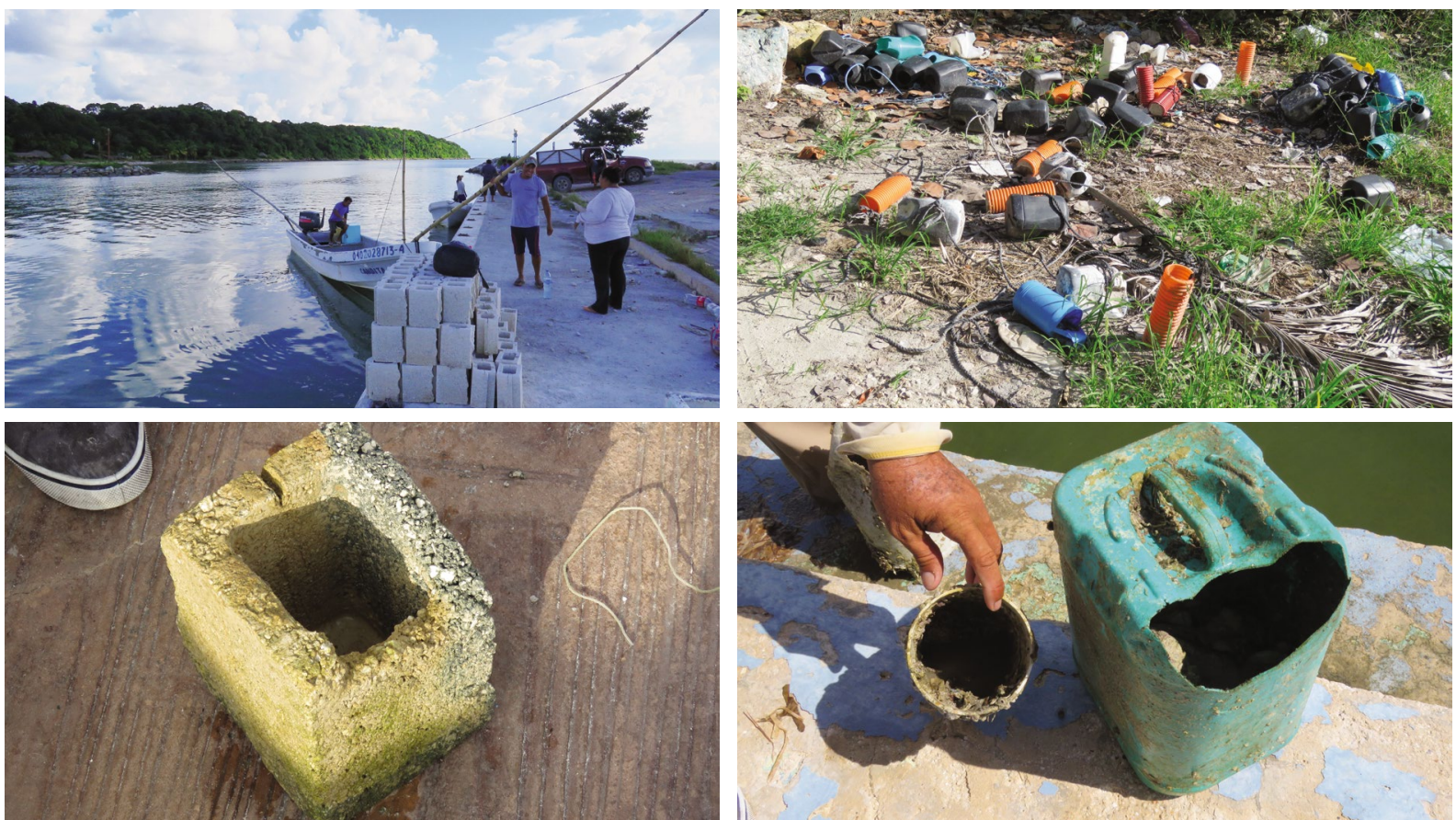

Fuente: Archivo de campo (2017). 
Precisamente, los buenos precios han propiciado que la captura del cefalópodo caiga bajo prácticas ilegales: en tiempo de veda -denominada popularmente 'temporada chica'- o con artes prohibidos o alegales (que no han sido reglamentados legalmente). En el primer caso destaca el buceo con compresora apoyado con el empleo de la fisga, el arpón o el gancho; lo suelen efectuar pescadores inexpertos, siendo frecuentes los accidentes laborales como la descompresión. En el segundo, sobresale el lanzamiento de arrecifes artificiales georreferenciados no autorizados -incluye todo tipo de materiales, como ramas de manglar, bovedillas de construcción y artefactos de hierro con neumáticos de caucho- que atraen a la hembra del pulpo para su enhueve; otro arte de este tipo son los botes de plástico pintados de negro y atados a un cordel en forma de línea (Figura 3). Como es lógico, la pesca irregular de pulpo genera fuertes tensiones en las comunidades pesqueras (estudiadas por Crespo, Jiménez y Nava, 2019). Es de considerar que, según el sector, un pescador legal puede capturar $25 \mathrm{~kg}$ de pulpo al día y un buzo ilegal superará los $100 \mathrm{~kg}$ con creces.

Otra escena de pesca ilegal acontece en la RBLP cuando varios pescadores irregulares alquilan una embarcación, denominada 'lancha-taxi', para transportarse a sus 'lugares', id est, puntos donde se sitúan sus arrecifes artificiales irregulares para bucearlos. Las embarcaciones cobran \$100 MXN [\$5,29 USD] por el traslado; es de mencionar que cada buzo comercializa personalmente su pesca (Figura 4). Además, estas lanchas contravienen la ley por trasladar a grupos de personas en un número superior al permitido.

FIGURA 4

LANCHA-TAXI EN LA RBLP (2017)

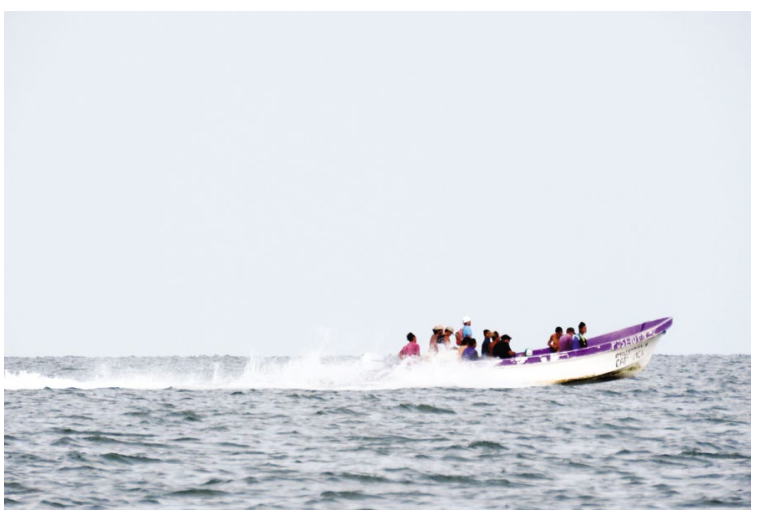

Fuente: Fotografía de los autores (2018).
Desde 2012, la captura del pepino de mar está vedada permanentemente en las costas de Campeche, sin embargo, el sector pesquero afirma que en las aguas de la RBLP se produce ilegalmente su captura: en el mercado ilegal internacional alcanza los $2.500 \mathrm{MXN} / \mathrm{Kg}$ (\$123,23 USD). Los pescadores de Isla Arena afirman que existen campamentos ilegales de procesado del pepino de mar en la RBLP y solicitan mayor vigilancia.

El camarón es otra especie que ofrece buenos resultados económicos, pero en Campeche se practica con embarcaciones mayores, salvo por algunas pequeñas cooperativas ubicadas en el municipio de Champotón. En los últimos años, la pesca ribereña de pulpo ha superado el volumen de la pesca de altura de camarón, lo que permite dimensionar la importancia de esta especie para la pesca campechana a pequeña escala (Gráfica 2). El tiburón también ofrece muy buenos resultados económicos por la demanda del mercado asiático de sus aletas, cartílagos y piel. La carne del cazón (tipo de tiburón) permanece en el mercado local al ser un producto típico de la gastronomía campechana.

GRÁFICA 2

SERIE HISTÓRICA (2006-2014) DE LA PRODUCCIÓN

PESQUERA (T) Y DE SU VALOR (MILES DE MXN) EN EL ESTADO DE CAMPECHE EN LA ZONA DE ESTUDIO

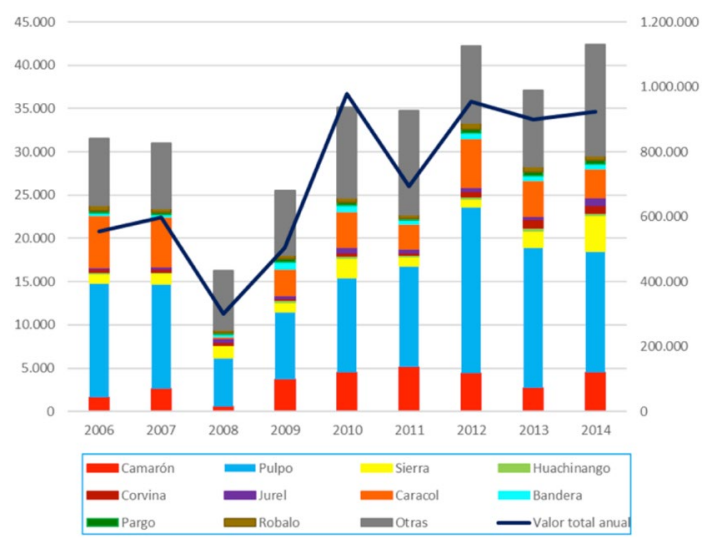

Fuente: CONAPESCA (2016). Elaboración propia.

\section{d) El reparto de la riqueza}

La distribución de las ganancias de una jornada de pesca suele tener variantes en función del tipo de UE y su tamaño. De acuerdo con la vinculación que tenga el permisionario con el acto de pescar, éste suele 
actuar de dos formas: cuando participa en él, para lo cual constituye su propio equipo de pesca, se apoya en uno o dos pescadores asalariados (según la especie a capturar); y cuando no participa, en mencionado caso el permisionario alquila su permiso y embarcación a un equipo de pesca a cambio de comprarle la mercancía a un precio acordado durante toda la temporada.

Cuando el permisionario participa en la pesca, al monto económico obtenido por la venta del producto se le sustrae la inversión que permite iniciar la actividad -normalmente gasolina, hielo y víveres-, la ganancia se distribuye 'a partes iguales' entre los integrantes del equipo y la embarcación; en otras ocasiones, si el secretario o chalán (ayudante del capitán) se desentiende de la compra de los artes de pesca, obtiene el $25 \%$ de la ganancia y el permisionario (en este caso coincide con la figura del capitán) el $75 \%$. Cuando el permisionario no participa, éste compra el producto al equipo que contrató; tras descontar la inversión, el monto se divide entre los integrantes del equipo (50\%) y el propietario de la embarcación (50\%), después el permisionario venderá el producto a un intermediario (coyote) o a un centro de acopio (denominado popularmente bodega) o a una congeladora a un precio superior (normalmente entre \$5 MXN) [\$0,26 USD] y \$10 MXN [\$0,52 USD] más caro por $\mathrm{kg}$, dependiendo de la especie, el volumen y el tipo de comprador). Es de apuntar que los pescadores sin permisos reparten sus ganancias bajo mencionados criterios.

El reparto de las ganancias de pesca en el sector social presenta formas diversas vinculadas al tamaño de la UE (número de socios, embarcaciones, permisos y trabajadores eventuales). Si es de corte familiar, lo normal es que la ganancia se distribuya en un $33 \%$ entre el capitán, el secretario y la sociedad cooperativa (propietaria de la embarcación); el producto se vende a pie de playa al mejor comprador. Si la cooperativa es de mayor tamaño, ésta compra el producto a quienes le trabajan (ya sean asociados o temporales); la ganancia se reparte como en el caso familiar, pero la cooperativa venderá a una bodega de mayor capacidad a un precio superior al que adquirió el género. La ganancia es para la cooperativa y se destinará al pago de los gastos de personal administrativo, mantenimiento de infraestructuras, compra de insumos, etc.

\section{e) La comercialización y los mercados}

Como se ha explicado, los permisionarios y las cooperativas de corte familiar venden sus productos o en el mercado local o a bodegas que disponen de un mayor alcance comercial. El Estado de Campeche dispone de 10 congeladoras de las cuales tres están certificadas por la Comisión Federal para la Protección contra Riesgos Sanitarios (COFEPRIS) para exportar: 'Compesmar', 'Marganzo' (ambas en S.Fco. de Campeche) y 'Congeladora Salomón' (en Sabancuy). Estas empresas adquieren el producto en centros de acopio, pero también disponen de una red de permisionarios y cooperativas familiares. Las congeladoras compran a las UE descritas los productos a un precio acordado durante toda la temporada: sellan sus relaciones verbalmente. Cuando las congeladoras requieren de más producto, lo adquieren en otras UE a un precio elevado. Esta situación genera malestar con algunos proveedores habituales, llegándose en algunos casos extremos a la ruptura del acuerdo.

Indicados arreglos comerciales se refuerzan con otro papel que han asumido las congeladoras: la de pequeñas entidades de ahorro y crédito popular; pues guardan un porcentaje de las ganancias de sus proveedores y en tiempos de gastos extraordinarios, como el inicio del curso escolar o en Navidad, se les devuelve la cantidad ahorrada; también otorgan pequeños préstamos sin interés a los pescadores en caso de necesidad. Son estrategias que utilizan las bodegas para asegurarse el producto.

En el trabajo de campo se identificaron diferentes procesos de comercialización que determinan el alcance comercial del producto: tipo de pescador, precio de la especie, ubicación del desembarque y presencia de acopiadores. Se configuran así flujos comerciales a diferentes escalas. La local se inicia a pie de playa y se continúa en un puesto del mercado de abastos o una pescadería. El pescador suele vender su producción a un pequeño acopiador que lo revenderá al consumidor en un modesto local; en otras ocasiones, el pescador tiene acceso a un puesto del mercado u otra sencilla instalación, lo que le permite obtener un valor añadido por la limpia y el procesado del producto que suele realizarlo su mujer. En los flujos nacionales participan empresas medianas que fungen como acopiadoras y disponen de la infraestructura suficiente para trasladar el producto por el territorio nacional. El trasporte se realiza por tierra, en camiones con equipo frigorífico, pudiendo ser propios o contratados. También se constatan traslados 
aéreos al centro del país desde el vecino aeropuerto yucateco de Mérida. Cuando las empresas se organizan y administran adecuadamente, aspiran a exportar, para ello es indispensable la certificación de COFEPRIS: de las 26 congeladoras del Estado de Campeche sólo tres están certificadas. Dato que revela un fuerte rezago en relación con el vecino Estado de Yucatán que contabiliza una red de 24 congeladoras habilitadas para exportar. Generalmente, para enviar al extranjero se utiliza la vía aérea -aeropuerto de Mérida- o marítima -Puerto Progreso-. Ambos centros, sitos en el Estado de Yucatán, funcionan como nodos concentradores y distribuidores de la producción pesquera de toda la península mexicana de Yucatán. Los cargamentos marítimos se dirigen a ciudades de EE.UU. como Miami, Nueva York o Nueva Orleans; también a países latinoamericanos como Panamá o Colombia. Mientras, los aéreos son para los mercados asiáticos, europeos y la costa oeste de EE.UU.

\section{f) Los desafíos de la pesca a pequeña escala en la RBLP}

A pesar de que la legislación indica que, para pescar comercialmente en las ANP se requiere de autorizaciones expedidas por SEMARNAT, en la entrevista realizada al director de la RBLP, éste desconoció el número de embarcaciones que habitualmente surcan las aguas protegidas y remitió a la CONAPESCA; tampoco pudo proporcionar los volúmenes extraídos anualmente en el ANP. Lo que le preocupaba era la utilización de artes de pesca ilegales y alegales. No es de olvidar que el manejo pesquero adecuado busca la abundancia y la salud de las especies. Y eso pasa por actualizar el programa de manejo de la RBLP: la falta de cumplimiento de los marcos regulatorios se convierte en un gran lastre en la búsqueda de la sostenibilidad.

En el aspecto socioeconómico numerosos pescadores viven en condiciones de pobreza, no reciben incentivos económicos, no están asegurados, capturan especies que tienen bajo valor comercial y, a veces, lo hacen contraviniendo las disposiciones legales y administrativas existentes. Debido a la persistente necesidad de empleo, con este tipo de prácticas, se enfrentan a la política de contención del esfuerzo pesquero que impide expedir más permisos. Ciertamente, los pescadores jornaleros o asalariados son los que viven en una situación económica más vulnerable en relación con los permisionarios o socios de cooperativas. En las entrevistas, la ma- yoría comentó que la pesca no genera ingresos suficientes para mantener a sus familias durante todo el año; este grupo es el que tiene el nivel de estudios más bajo: lo común es tener la educación primaria terminada o la secundaria inacabada. Los pescadores tienen un alto grado de incertidumbre en sus ingresos diarios, el comportamiento del mar y de las especies a capturar es caprichoso, lo que conduce a ganancias variables o incluso a la pérdida de la inversión inicial. Los períodos cuyas condiciones climáticas no favorecen las capturas (normalmente entre enero y abril por la abundancia de 'los nortes') se aprovechan para el mantenimiento de la embarcación, los artes y la puesta a punto del motor. Asimismo, comentaron que cada vez deben desplazarse más lejos de la línea de costa para acceder a nuevos caladeros, lo que da lugar a un incremento sustancial de la inversión de gasolina y hielo. Un pescador de S. Fco. de Campeche afirmó que en 1990 invertía 20 I cada vez que salía a navegar, en 2016 necesitaba 100 I. Además, el precio de la gasolina Magna ha ido incrementándose sustancialmente, si en diciembre del 2000 el litro ascendía a \$5,27 MXN/I (\$0,58 USD), en enero de 2017 costaba \$16,55 MXN/I (\$0,77 USD). Es evidente que el pescador se ha beneficiado poco del incremento del valor de los productos del mar porque el precio de los insumos también lo ha hecho considerablemente. El desarrollo sostenible vincula los aspectos económico y social y sus efectos en el medio natural. En este sentido, si la calidad de vida de los pescadores ribereños es baja, si no se reconoce su importante participación en la cadena productiva, si están sujetos a los precios que imponen los intermedios, significa que se ha trabajado poco para eliminar la pobreza de este sector y que se está descuidando su contribución para alcanzar la seguridad alimentaria.

\section{g) Esbozos sobre el papel de las mujeres en la pesca}

En la zona de estudio, como respuesta a las tradicionales nociones sobre la división del trabajo, las mujeres no suelen participar como pescadoras, su papel es secundario o complementario a esa labor. Aquéllas involucradas en actividades afines a la pesca ribereña e industrial intervienen en la fase de poscaptura: procesado y venta. Este panorama se repite en otros estados de México (López y López, 2018).

Es común que las mujeres obtengan ingresos a partir de la limpia y el fileteo del pescado; dependiendo del destino de los productos, esos trabajos se realizan en 
espacios diferenciados: cuando la venta es local, tienen lugar en los hogares y en las instalaciones de los mercados; cuando se trata de productos que se comercializan en redes más amplias, se ejecutan en las plantas comercializadores que cumplen por lo general con toda normativa laboral y sanitaria (Figura 5).

Las mujeres que intervienen en la venta, frecuentemente disponen de un puesto en el mercado local de abastos y en ocasiones, consiguen un valor añadido al regentar pequeños restaurantes familiares. La FAO (2017a) ha constatado ese perfil de emprendedora en algunas regiones en desarrollo. En el trabajo de campo, se observaron casos puntuales de permisionarias que habían conseguido que la administración les traspasase la titularidad de los permisos de sus difuntos familiares: padre, esposo o hijo (Uc et al. 2017). Las permisionarias alquilan sus permisos y embarcaciones, compran el producto a pie de playa a sus equipos y después, lo venden más caro a una bodega o congeladora.

Especial mención merece el cazón, producto que se comercializa ahumado (asado según la jerga regional) y tiene alta demanda por su uso en la cocina local. Este trabajo permite elevar su precio en un $50 \%$, sin embargo, se trata de un trabajo que se realiza artesanalmente en los hogares, exponiendo a las mujeres y a sus familias al humo que se genera a partir de la combustión de carbón vegetal (FAO, 2017b).

Así pues, se diferencian dos perfiles genéricos de mujeres vinculadas a la posproducción (todos agregan valor). Por un lado, las mujeres que procesan los productos pesqueros en sus hogares y no lo hacen bajo los criterios de un trabajo regulado (situación que dificulta acceder a cifras o cálculos registrados), operan de manera autónoma y/o con pagos a destajo, normalmente sin prestaciones laborales. Por otro, las asalariadas por empresas, sus contratos son más heterogéneos al estar relacionados con sus actividades (dirección de control de calidad, administración, limpieza, procesado...). Normalmente, las empleadas tienen una formación reglada, una remuneración fija y periódica, son mejor pagadas y acceden a todos sus derechos laborales.

\section{CONCLUSIONES}

Durante la investigación se constató que los Estados Unidos Mexicanos están comprometidos con alcanzar para el año 2030 la meta 14 que propone el fortalecimiento de la legislación y la gestión de las zonas pesqueras. El marco legal y el aparato gestor pueden considerarse adecuados, pero requieren ser actualizados, como la Carta Nacional Pesquera y los planes de manejo de las ANP; sin embargo, la gestión presenta deficiencias como la mejorable coordinación entre las administraciones de pesca y ambiente, el desbordamiento de la legalidad por la dinámica de la actividad -esencialmente expresada en la utilización de artes alegales e ilegales-. De esta manera, resulta de gran complejidad poner freno a la pesca excesiva, ilegal y no reglamentada.

La meta 14.9 considera que los pescadores artesanales debieran acceder a los mercados, en la RBLP se ha constatado que esta situación ha traído consigo

FIGURA 5

MUJERES EN EL PROCESO DE POSPRODUCCIÓN EN MERCADO DE SAN FRANCISCO DE CAMPECHE (2017, IZQ.) Y FÁBRICA DE PUERTO PROGRESO (2019, DCHA.)
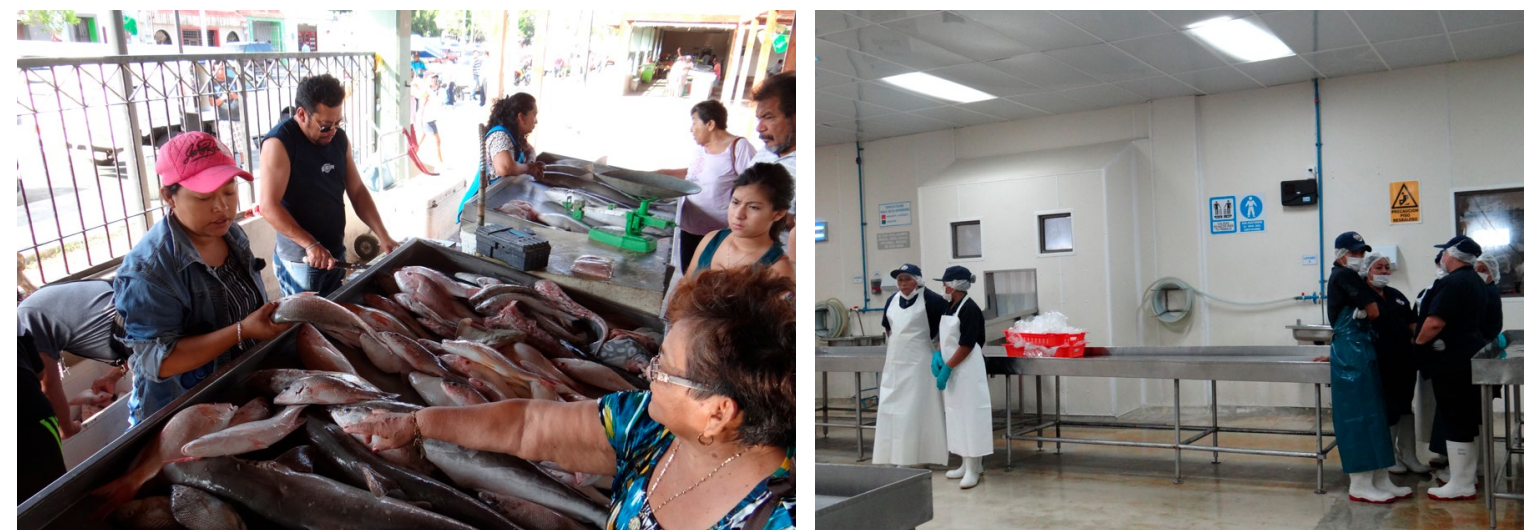

Fuente: Fotografía de Jiménez-Pelcastre (2017/2019). 
el aumento del precio de determinados productos como el pulpo y los derivados del tiburón, entre otros. Este hecho puede considerarse positivo pues ha incrementado las ganancias de los pescadores; ha propiciado flujos migratorios temporales de trabajadores del interior a los puertos campechanos para complementar ingresos gracias a las ganancias obtenidas de la actividad pesquera vinculada fundamentalmente a la captura de pulpo; también ha dado lugar a inversiones destinadas a la mejora de las infraestructuras pesqueras (embarcaciones, motores, artes, instalaciones de almacenamiento y manipulación) con el fin de ser certificadas y así mantener y/o ampliar los canales de comercialización hacia los mercados asiáticos, europeos y estadounidenses.

La otra cara de la moneda ha sido el incremento del número de pescadores sin permiso que ponen en jaque a la administración competente; el aumento de los accidentes laborales (ahogamientos y descompresiones entre los pescadores no profesionales); la reducción de los recursos pesqueros; el acrecentamiento en la inversión para llegar a caladeros cada vez más lejanos, lo que redunda también en la seguridad de la navegación (las embarcaciones ribereñas con motores de alto caballaje llegan incluso a desplazarse a $100 \mathrm{~km}$ de la línea de costa). Estas realidades demuestran el interés de una intervención pública para ser superadas. Así, es necesario aumentar los esfuerzos en capacidad de gestión, renovar las herramientas de manejo y poner en práctica políticas públicas más dinámicas, capaces de hacer frente a los desafíos que presenta una actividad económica tan cambiante como vulnerable. Queda demostrado que el acceso a los mercados internacionales debe darse bajo unas realidades administrativas consolidadas y ágiles que corrijan posibles efectos indeseados tanto ambientales como socioeconómicos de una forma adecuada y expedita.

Desafortunadamente, México en general y la zona de estudio en particular no disponen de datos que visibilicen y valoren el papel de las mujeres en la pes-

\section{NOTAS}

1 Nuevo dato ofrecido en comunicado, el 21 de noviembre de 2019, por la Dirección General de Geomática de la Comisión Nacional para el Conocimiento y Uso de la Biodiversidad (CONABIO).

2 Los petenes son pequeñas islas de vegetación arbórea -fundamentalmente de selva mediana perennifolia, subperennifolia y manglar-inmersas en medio de amplias zonas inundables de tipo pan- ca. El trabajo de campo ofrece una aproximación cualitativa interesante pero aún se desconocen cuántas mujeres laboran en el sector, en qué condiciones y el valor económico que aportan. Es de considerar que la ausencia de dicha información se debe, en parte, al carácter informal de su trabajo, y a sesgos y procesos incompletos en la captura de la información estadística (no desagregan los datos por género, por ejemplo). Todo ello contribuye a ignorar cuantitativamente el aporte de las mujeres en el ámbito pesquero y por tanto, a no poder emprender acciones acertadas que las consideren.

Se evidencia que la geografía en general y el posicionamiento que ofrece la Organización Espacial, apoyado en una metodología transversal y coherente, ofrecen resultados clarificadores que coadyuven a políticas públicas acertadas.

\section{DEDICATORIA}

A la memoria de mi querido padre José Manuel Crespo Cuadra.

\section{RECONOCIMIENTOS}

Sirvan estas líneas para agradecer a Araceli Jiménez Pelcastre y Annie Gaborit sus sugerencias, siempre precisas y acertadas. Por su generosidad con la investigación, inestimable fue la colaboración de las personas del sector pesquero comercial ribereño del Estado de Campeche. No podemos olvidar el trabajo anónimo de los evaluadores, por ello, les damos las gracias. Esta investigación fue financiada por el Programa UNAM-DGAPA-PAPIIT. Clave IA300716. Organización del sector pesquero comercial ribereño en las áreas naturales protegidas del Estado de Campeche.

tanoso (Barrera, 1982). Bordean la península de Yucatán, siendo abundantes en la porción centro oriental del Estado de Quintana Roo y en el noroeste del Estado de Campeche (Durán, 1995).

3 La LGEEPA en su Sección II, 'Tipos y careacterísticas de las Áreas Naturales Protegidas', artículo 46, considera las siguientes categorías federales de conservación de la naturaleza: Reserva de la Bios- 
fera (1), Parque Nacional (2), Monumento Natural (3), Área de Protección de Recursos Naturales (4), Área de Protección de Flora y Fauna (5) y Santuario (6). Por medio de sus legislaciones, los estados y los municipios mexicanos establecen sus propias figuras de conservación de la naturaleza.

4 El artículo $4^{\circ}$ de la Ley de la Economía Social y Solidaria define el sector social como aquél integrado por las siguientes formas de organización social: ejidos, comunidades, organizaciones de trabajadores, sociedades cooperativas, empresas que pertenezcan mayoritaria o exclusivamente a

\section{REFERENCIAS BIBLIOGRÁFICAS}

Abler, R., Adams J. S., y Gould, P. (1972). Spatial Organization; the Geographer's View of the World. Nueva Jersey, EE. UU.: Prentice Hall.

Álvarez, C., Gajardo, C., y Ther, F. (2016). Actores y conflictos territoriales en una figura de administración pública de la pesca artesanal: El caso de la zona contigua en las regiones de Los Lagos y de Aysén, sur de Chile. Magallania (Punta Arenas), 44(1), 131-147. doi https://dx.doi.org/ $10.4067 / \mathrm{S} 0718-22442016000100008$

Aquije, H. F., y Ortiz, L. (2017). Relación de la pesca industrial de anchoveta con la pesca artesanal: evidencia del caso peruano. (Tesis de licenciatura). Universidad de Piura, Lima, Perú.

Barrera, A. (1982). Los petenes del noroeste de Campeche. Su exploración ecológica en perspectiva. Biótica 7(2), 163-169.

Campos, G. J., y Crespo, J. M. (2018). Organización espacial de la pesca comercial ribereña en el Área de Protección de Flora y Fauna Laguna de Términos, México. Investigaciones Geográficas, 96(0): 0-0. doi https://dx.doi.org/10.14350/rig.59558

Cóccaro, J. M., Le Bail, J., Gómez, O., y Boetto, A. (27 de octubre del 2000). La minería pesquera ¿Argentina? Actas del Segundo Encuentro Internacional Humboldt. Edición en CD. Mar del Plata, Argentina.

Comisión Nacional de Acuacultura y Pesca [CONAPESCA]. (2016). Información estadística por especie y entidad. México: SEMARNAT. Recuperado de https://www.conapesca.gob.mx/wb/cona/ informacion_estadistica_por_especie_y_entidad los trabajadores y en general, de todas las formas de organización social para la producción, distribución y consumo de bienes y servicios socialmente necesarios (DOF, 12 de abril de 2019).

5 Según el Servicio de Administración Tributaria las personas morales son agrupaciones de personas con un fin en común, siendo las personas físicas, individuos.

6 Las conversiones a dólares estadounidenses (\$USD) aplicados para las fechas referidas se efectúan considerando los cambios oficiales ofrecidos por el Banco Nacional de México serie histórica.

Comisión Nacional de Acuacultura y Pesca [CONAPESCA]. (2017). Anuario Estadístico de Acuacultura y Pesca 2017. Comisión Nacional de Acuacultura y Pesca. México: SAGARPA. Recuperado de http:// www.conapesca.gob.mx/work/sites/cona/ dgppe/2017/ANUARIO_ESTADISTICO_2017.pdf

Comisión Nacional de Áreas Naturales Protegidas [CONANP]. (2006). Programa de Conservación y Manejo Reserva de la Biosfera Los Petenes. México: CONANP. Recuperado de https://simec. conanp.gob.mx/pdf_libro_pm/91_libro_pm.pdf

Comisión Nacional de Áreas Naturales Protegidas [CONANP]. (2018). Sistema de Información y Monitorio y Evaluación para la Conservación. México: SEMARNAT. Recuperado de https://simec. conanp.gob.mx/consulta_fichas.php

Comisión Nacional de Áreas Naturales Protegidas [CONANP]. (2019). Información espacial. Descarga de archivos SHAPE. Recuperado de http://sig. conanp.gob.mx/website/pagsig/info_shape.htm

Coraggio, J. L. (1976). Centralización y concentración en la configuración espacial argentina. Instituto Latinoamericano de Planificación Económica y Social. Santiago de Chile, Chile. Recuperado de https://repositorio.cepal.org/handle/11362/33648

Crespo, J. M., y Jiménez, A. (2016). Organización del sector pesquero comercial ribereño en la Reserva de la Biosfera El Vizcaíno (México). Revista Geográfica Venezolana, 57(2), 236-259. Recuperado de http:// www.saber.ula.ve/handle/123456789/42729

Crespo, J. M., y Jiménez, A. (2017). Organización e impacto territorial de la actividad pesquera comercial ribereña en la Reserva de la biosfera Ría 
Celestún (México). Anales de Geografía de la Universidad Complutense, 37(2), 297-324. doi http://dx.doi.org/10.5209/AGUC.57727

Crespo, J. M., y Jiménez, A. (2018). Orígenes y procesos territoriales del cooperativismo pesquero en la zona Pacífico Norte de Baja California Sur, México, 18501976. América Latina en la Historia Económica, 25(1), 196-238. Recuperado de http://alhe.mora. edu.mx/index.php/ALHE/article/view/841

Crespo, J. M., Jiménez, A., y Nava, J. D. (2019). Tensiones y conflictos territoriales en la pesca ribereña del Estado de Campeche, México (20132018). Boletín de la Asociación Española de Geografía, 82(0), doi http://dx.doi.org/10.21138/ bage. 2764

Crespo, J. M., y Rivera, M. G. (2017). Organización y transformaciones de la pesca comercial ribereña en el Parque Nacional Bahía de Loreto (Baja California Sur, México). Ager, Revista de Estudios sobre Despoblación y Desarrollo Rural, 23(0), 5996. Recuperado de http://ruralager.org/wpcontent/uploads/Ager-23-03-Crespo-03.pdf

Diario Oficial de la Federación [DOF]. (12 de abril de 2019). Ley de la Economía Social y Solidaria, Reglamentaria del Párrafo Octavo del Artículo 25 de la Constitución Política de los Estados Unidos Mexicanos, en lo referente al sector social de la economía. Texto vigente, última reforma. Ciudad de México, a 12 de abril de 2019. Recuperado de https://www.gob.mx/inaes/documentos/ ley-de-la-economia-social-y-solidaria-36064

Diario Oficial de la Federación [DOF]. (19 de enero de 2018). Ley General de Sociedades de Cooperativas. Texto vigente, última reforma. Ciudad de México, a 23 de noviembre de 2017. Recuperado de http://www.diputados.gob.mx/LeyesBiblio/ pdf/143_190118.pdf

Diario Oficial de la Federación [DOF]. (21 de mayo de 2014). Reglamento de la Ley General del Equilibrio Ecológico y Protección al Ambiente en Materia de Áreas Naturales Protegidas. Texto vigente, última reforma. Ciudad de México, a 16 de mayo de 2014. Recuperado de http://www. diputados.gob.mx/LeyesBiblio/regley/Reg_ LGEEPA_ANP.pdf

Diario Oficial de la Federación [DOF]. (24 de abril de 2018). Ley General de Pesca y Acuacultura Sustentables. Texto vigente, última reforma. Ciudad de México, a 22 de febrero de 2018. Recuperado de http://www.diputados.gob.mx/LeyesBiblio/ pdf/LGPAS_240418.pdf

Diario Oficial de la Federación [DOF]. (5 de julio de 2016). Acuerdo por el cual se expide el Programa Nacional de Investigaciones Oceanográficas. Texto vigente, última reforma. Ciudad de México, a 22 de junio de 2016. Recuperado de http://dof. gob.mx/nota_detalle.php\%3Fcodigo\%3D544350 3\%26fecha\%3D05/07/2016

Diario Oficial de la Federación [DOF]. (5 de junio de 2018). Ley General del Equilibrio Ecológico y Protección al Ambiente. Texto vigente, última reforma. Ciudad de México, a 26 de abril de 2018. Recuperado de http://www.diputados.gob.mx/ LeyesBiblio/pdf/148_050618.pdf

Diyakonov, V., Gramoteyeva, L., y Kalashnicova, T. (1976). Regional Economic Complexes as the principal forms of planned solution of spatial problems of organization of the socialist economy. Geoforum, 7(3), 175-181. doi https://doi. org/10.1016/0016-7185(76)90030-0

Durán, R. (1995). Diversidad florística de los petenes de Campeche. Acta Botánica Mexicana, 31, 7384. Recuperado de https://www.redalyc.org/ pdf/574/57403108.pdf

Felicidades, J., y Piñeiro, M. A. (2018). El desarrollo local participativo en las zonas de pesca. Modelos territoriales de los GALP del Atlántico español. En Márquez, J. A. (Ed.), Sistemas productivos con anclaje territorial (pp. 43-56). Huelva, España: Servicio de Publicaciones Universidad de Huelva.

Food and Agriculture Organization of the United Nations [FAO]. (2014). Directrices voluntarias para lograr la sostenibilidad de la pesca en pequeña escala en el contexto de la seguridad alimentaria y la erradicación de la pobreza. Roma, Italia: FAO. Recuperado de http://www.fao.org/cofi/42019067220930ec966ce487c78770ac854ab5.pdf

Food and Agriculture Organization of the United Nations [FAO]. (2017a). Promover la igualdad de género y el empoderamiento de las mujeres en la pesca y la acuicultura. Roma, Italia: FAO. Recuperado de http://www.fao.org/3/a-i6623s.pdf

Food and Agriculture Organization of the United Nations [FAO]. (2017b). Los nuevos hornos para ahumar pescado llegan a Asia. Roma, Italia: FAO. Recuperado de http://www.fao.org/gender/ news/detail/es/c/1105061/ 
Food and Agriculture Organization of the United Nations [FAO]. (8 de junio de 2017). Acabar con la pesca ilegal es fundamental para lograr la meta de los océanos saludables. Roma, Italia: FAO. Recuperado de http://www.fao.org/news/story/it/ item/892865/icode/

Food and Agriculture Organization of the United Nations [FAO]. 2018. El estado mundial de la pesca y la acuicultura. Cumplir los objetivos de desarroIlo sostenible. Roma, Italia: FAO. Recuperado de http://www.fao.org/3/i9540es/I9540ES.pdf

Frolova, M. (2002). La evolución de la Geografía y del trabajo del geógrafo en Rusia. Scripta Nova, Revista Electrónica de Geografía y Ciencias Sociales, 6(119), 80. Recuperado de http://www.ub.edu/ geocrit/sn/sn119-80.htm

George, P. (1976). Difficultés et incertitudes de la géographie. Annales de géographie, 467, 48-63. Recuperado de http://www.persee.fr/doc/ geo_0003-4010_1976_num_85_467_17408

Hernández, R. (1995). Democracia, espacio y organización territorial: elementos para una reflexión teórica (Tesis de licenciatura). Universidad Nacional Autónoma de México, México, Estados Unidos Mexicanos Recuperado de http://132. 248.9.195/ppt1997/0230130/Index.html

Instituto Nacional de Estadística y Geografía (INEGI). (2017a). INEGI. Cuéntame Economía. Actividades económicas primarias. Pesca. México: Instituto Nacional de Estadística, Geografía e Informática. Recuperado de http://cuentame.inegi.org.mx/ economia/primarias/pesca/default.aspx?tema $=\mathrm{E}$

Instituto Nacional de Estadística y Geografía (INEGI). (2017b). INEGI. Directorio Estadístico de Unidades Económicas. Recuperado de https://www. inegi.org.mx/app/mapa/denue/

Instituto Nacional de Estadística y Geografía [INEGI]. (2010). Censo de Población y Vivienda 2010. México: Instituto Nacional de Estadística, Geografía e Informática. Recuperado de https://www.inegi. org.mx/programas/ccpv/2010/

Kostrowicki, J. (1975). Un concepto clave: organización espacial. Revista Geográfica de América Central, 1(2), 51-66. Recuperado de http://www. revistas.una.ac.cr/index.php/geografica/article/ download/2067/1963
López, I., y López, R. (2018). Las mujeres y el sector pesquero en México. dataMares. InteractiveResource. doi https://doi.org/10.13022/M30K9N

Martínez, S. T. (2014). Impacto socioeconómico de la pesca en la Presa Jalpan, Querétaro (Tesis de licenciatura). Universidad Nacional Autónoma de México, México, Estados Unidos Mexicanos. Recuperado de http://132.248.9.195/ptd2014/ agosto/0717656/Index.html

Mestre, M. M., Ortega, M., Musoles, L., y Ramos, J. (2015). Conflictos socio-ambientales de la acuicultura del camarón en Centroamérica. Un análisis desde la justicia ambiental. Barcelona, España: Fundació Ent.

Moreno, D. (2019). La pesca en la Bahía de Mazarrón: pasado, presente y futuro. Mazarrón, España: Ayuntamiento de Mazarrón. Recuperado de https://dialnet.unirioja.es/servlet/libro? codigo $=730025$

Organización de las Naciones Unidas [ONU]. (2015). Objetivos del Desarrollo Sostenible. 17 objetivos para transformar nuestro mundo. Nueva York, EE.UU.: ONU. Recuperado de http://www.un.org/ sustainabledevelopment/es/oceans/

Organización de Naciones Unidas [ONU]. (2018). Análisis de los compromisos voluntarios aplicables a la basura marina y los microplásticos, de conformidad con la resolución 3/7. Informe de la Directiva Ejecutiva. Nueva York, EE.UU.: ONU. Recuperado de https://papersmart.unon.org/resolution/ uploads/k1804199.pdf

Palamarchuk, M. M., Privalovskaya, G. A., Gorlenko, I. A., y Runova, T. G. (1976). The role of environment and natural resources in territorial organization of the USSR economy. Geoforum 7(3), 167173. Recuperado de http://linkinghub.elsevier. com/retrieve/pii/0016718576900294

Phillipson, J., y Symes, D. (2015). Finding a Middle Way to Develop Europe's Fisheries Dependent Areas: The Role of Fisheries Local Action Groups. Sociologia Ruralis, 55(3), 343-359. doi https://doi. org/10.1111/soru.12098

Sánchez, Á., Mollinedo, G., y Propin, E. (2012). Estructura territorial del turismo en Guatemala. Investigaciones Geográficas, 0(78), 104-121. doi http://dx.doi.org/10.14350/rig.32473

Sánchez, G. (7 de junio de 2017). Detectan 4 Mil embarcaciones ilegales en Campeche. Noticieros Te- 
levisa. Recuperado de https://noticieros. televisa.com/ultimas-noticias/detectan4-mil-embarcaciones-pesqueras-ilegales-campeche/

Saushkin, J. G. (1962). Economic geography in de URSS. Economic Geography, 38(1), 28-37. doi http://dx.doi.org/10.2307/142323

Sepúlveda, R. D. (2015). Conflictos socioambientales en la cuenca baja del río Sinu, Colombia. Revista Direitos Emergentes na Sociedade Global, 4(1), 23-43. Recuperado de https://periodicos.ufsm. br/index.php/REDESG/article/view/20377\#. XFShglxKjIX

Strauss, A. M., Corbin, J., y Zimmerman, E. (2002). Bases de la investigación cualitativa: técnicas y procedimientos para desarrollar la teoría fundamentada. Medellín, Colombia: Universidad de Antioquia. Recuperado de https://diversidadlocal. files.wordpress.com/2012/09/bases-investigacioncualitativa.pdf

Uc, M., Molina, D., Vázquez, V., Pérez, J. C., y Gurri, F. (2017). Permisos de pesca y relaciones de género en Isla Arena, Campeche. Agricultura, Sociedad y Desarrollo, 14(3), 383-404. doi https:// doi.org/10.22231/asyd.v14i3.642

Van de Walle, G., Gomes da Silva, S., O'Hara, E., y Soto, P. (2015). Achieving Sustainable Develop- ment of Local Fishing Interests: The Case of Pays d'Auray flag. Sociologia Ruralis, 55(3), 360-377. doi https://doi.org/10.1111/soru.12097

Villerías, S. (2009). Análisis espacial de la pesca en la Costa Chica de Guerrero (Tesis doctoral). Universidad Nacional Autónoma de México, Ciudad de México, Estados Unidos Mexicanos. Recuperado de http://132.248.9.195/ptd2009/junio/ 0644221/Index.html

Villerías, S., y Sánchez, A. (2010). Perspectiva territorial de la pesca en la Costa Chica de Guerrero. Investigaciones Geográficas, Boletín del Instituto de Geografía, 71(0), 43-56. doi http://www.scielo. org.mx/scielo.php?script=sci_arttext\&pid $=$ S0188-46112010000100005

Yurkievich, G., y Sánchez, Á. (2016). Estructura territorial de la actividad pesquera en Guaymas, Sonora. Investigaciones Geográficas, 91(0), 152167. doi http://dx.doi.org/10.14350/rig.49937

Zucco, C. A., y Tomás, W. (2004). Diagnostico do conflicto entre os pescadores profissionais artesanais e as populações de jacares (Caiman yacare) e ariranhas (Pteronura brasiliensis) no pantanal. IV Simposio sobre Recursos Naturais e Socio-economicos do Pantanal Corumba/MS. Vol. 23. 2004. Recuperado de http://cort.as/-EQNQ 


\section{ANEXO}

UNIVERSIDAD NACIONAL AUTÓNOMA DE MÉXICO

COLEGIO DE GEOGRAFÍA

\section{Pesca comercial ribereña en la Reserva de la Biosfera Los Petenes (RBLP)}

La siguiente entrevista es de carácter personal y se garantizará el anonimato total del individuo en cuestión, dicha entrevista se hace con el fin de conocer la organización territorial de pesca en la RBLP.

Fecha:

Número de encuesta

Municipio

Localidad

\section{ASPECTOS SOCIECONÓMICOS DEL PESCADOR}

\begin{tabular}{|c|c|c|c|c|}
\hline \multicolumn{5}{|l|}{ 1.- Sexo } \\
\hline Hombre & & Mujer & & \\
\hline \multicolumn{5}{|l|}{ 2.- Edad } \\
\hline \multicolumn{5}{|l|}{ 3.- ¿Qué estudios tiene? } \\
\hline 4.- Lugar de nacimiento & Estado & Municipio & & Localidad \\
\hline 5.- Lugar de residencia & Estado & Municipio & & Localidad \\
\hline \multicolumn{5}{|l|}{ 6.- Estado civil } \\
\hline Soltero & Casado & Viudo & Divorciado & Unión libre \\
\hline \multicolumn{5}{|c|}{ 7.- ¿Cuántas personas viven con usted, edad y ocupación? } \\
\hline \multicolumn{5}{|c|}{ 8.- ¿Usted vive de la pesca comercial ribereña? } \\
\hline & & & No & \\
\hline \multicolumn{5}{|c|}{ 9.- ¿A qué edad empezó a pescar? } \\
\hline \multicolumn{5}{|c|}{ 10.- ¿Cuántos meses al año se dedica a la pesca comercial ribereña? } \\
\hline \multicolumn{5}{|c|}{ 11.- ¿A qué se dedica cuando no pesca? } \\
\hline \multicolumn{5}{|c|}{ 12.- ¿Por qué se dedica a la pesca comercial ribereña? } \\
\hline \multicolumn{5}{|c|}{ 13.- ¿De cuántas personas está conformado el equipo que va a pescar con usted? } \\
\hline \multicolumn{5}{|c|}{ 14.- ¿Qué prestaciones tiene? } \\
\hline \multicolumn{5}{|c|}{ 15.- ¿Cómo califica su estado de salud? } \\
\hline Muy malo & Malo & Bueno & & Muy bueno \\
\hline Indicar padecimientos: & & & & \\
\hline
\end{tabular}




\section{ASPECTOS TÉCNICOS: MÉTODOS, HERRAMIENTAS, TECNIFICACIÓN}

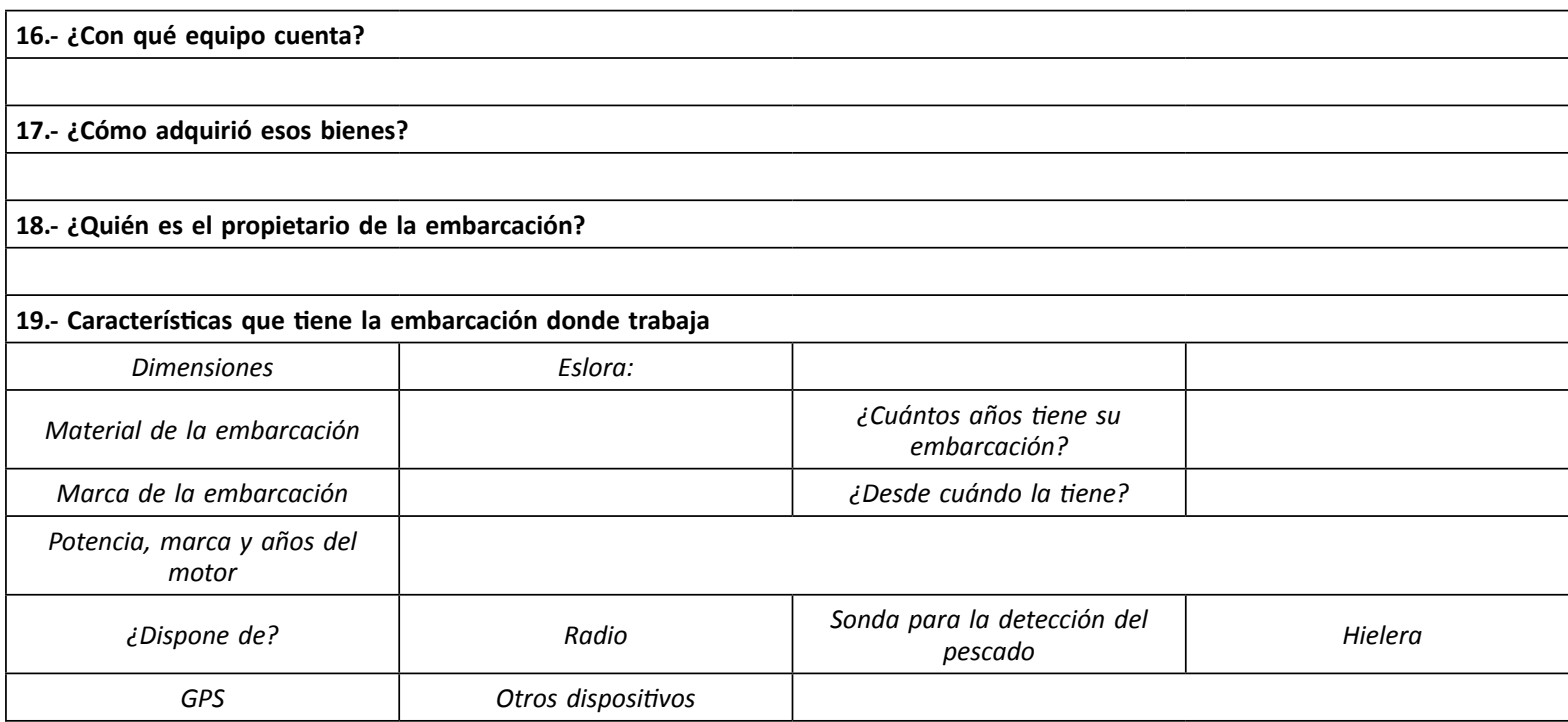

20.- ¿Sabe si existe algún programa gubernamental que apoye a los pescadores para adquirir o renovar equipos? ¿Se ha beneficiado de alguno?

21.- ¿Qué tipo de gastos asociados a la pesca comercial ribereña suele tener por cada salida y en cuánto lo estima? (gasolina, alimento, otro)

22.- Haciendo un balance entre sus ingresos y sus gastos, ¿Considera que las ganancias obtenidas son suficientes para cubrir sus gastos cotidianos y mantener a su familia?

23.- ¿Tiene algún permiso para pescar? / ¿Usted lo pagó? / ¿Cuál es el importe? / ¿Cada cuánto lo renueva?

24.- ¿En qué forma de organización social se encuentra registrado para practicar la pesca comercial ribereña? ¿Qué ventajas tiene?

\begin{tabular}{|c|c|c|c|}
\hline Cooperativa pesquera & Permisionario & Sociedad de producción rural & Sociedad de solidaridad social \\
\hline Unión de pescadores & Pescador libre & \multicolumn{2}{|c|}{ Otra: } \\
\hline Nombre de la cooperativa & & Nombre del permisionario & \\
\hline Nombre de la sociedad & & $\begin{array}{l}\text { Nombre de la unión de } \\
\text { pescadores }\end{array}$ & \\
\hline
\end{tabular}

25.- ¿Cómo se distribuyen los beneficios de la pesca entre sus compañeros?

\section{6.- ¿Están federados?}

\section{7.- ¿Cómo se llama su federación?}

\section{8.- ¿Funciona?}

29.- ¿Cuáles son sus cometidos?

30.- ¿Cómo mejorarían su federación? 


\title{
III. EL ARTE DE LA PESCA Y ESPACIOS DE PRODUCCIÓN ALMACENAJE Y COMERCIALIZACIÓN
}

\author{
31.- ¿Cuál es su puesto base? *Dónde pesca \\ 32.- ¿A qué pesquería se traslada más lejos de su puesto base?
}

33.- ¿Cuánto tiempo tiene que navegar?

34.- ¿Utiliza campamento pesquero? ¿Dónde se encuentra? ¿Cuánto tiempo pasa en él?

35.- ¿Usted almacena lo que pesca?

36.- ¿Dónde almacena lo que pesca? ¿En dónde se encuentra dicho centro? (municipio, localidad, colonia y calle)

37.- ¿Vende su producción o la consume?/ ¿A quién le vende su producción? / ¿Sabe dónde venden lo que pesca? (Al por mayor o al por menor)

38.- ¿Cuáles son las cuatro las pesquerías más importantes de la región?

\begin{tabular}{l|l}
\hline $1 .-$ & 3. \\
\hline $2 .-$ & 4.
\end{tabular}

39.- ¿Cuáles son las especies que pesca y en qué temporada?

\begin{tabular}{|c|c|c|c|c|c|c|c|c|c|c|c|c|}
\hline Especie & Ene & Feb & Mar & Abr & May & Jun & Jul & Ago & Sep & Oct & Nov & Dic \\
\hline 1.- & & \\
\hline 2.- & & \\
\hline 3.- & & \\
\hline 4.- & & \\
\hline 5.- & & \\
\hline 6.- & &
\end{tabular}

40.- ¿Usted cree que la pesca tiene problemas con otras actividades económicas?

\begin{tabular}{|l|l|}
\hline Sí No & No \\
\hline 41.- En caso de que la pregunta anterior sea afirmativa ¿Podría decir cuáles? \\
\hline
\end{tabular}

42.- ¿Qué es para usted más importante?

\begin{tabular}{|l|l|l} 
Precio de venta & Volumen de captura & Permiso
\end{tabular}

43.- ¿Comparte información con otros pescadores? ¿De qué tipo? 


\section{LA INFLUENCIA DEL ÁREA NATURAL PROTEGIDA EN LA ACTIVIDAD PESQUERA}

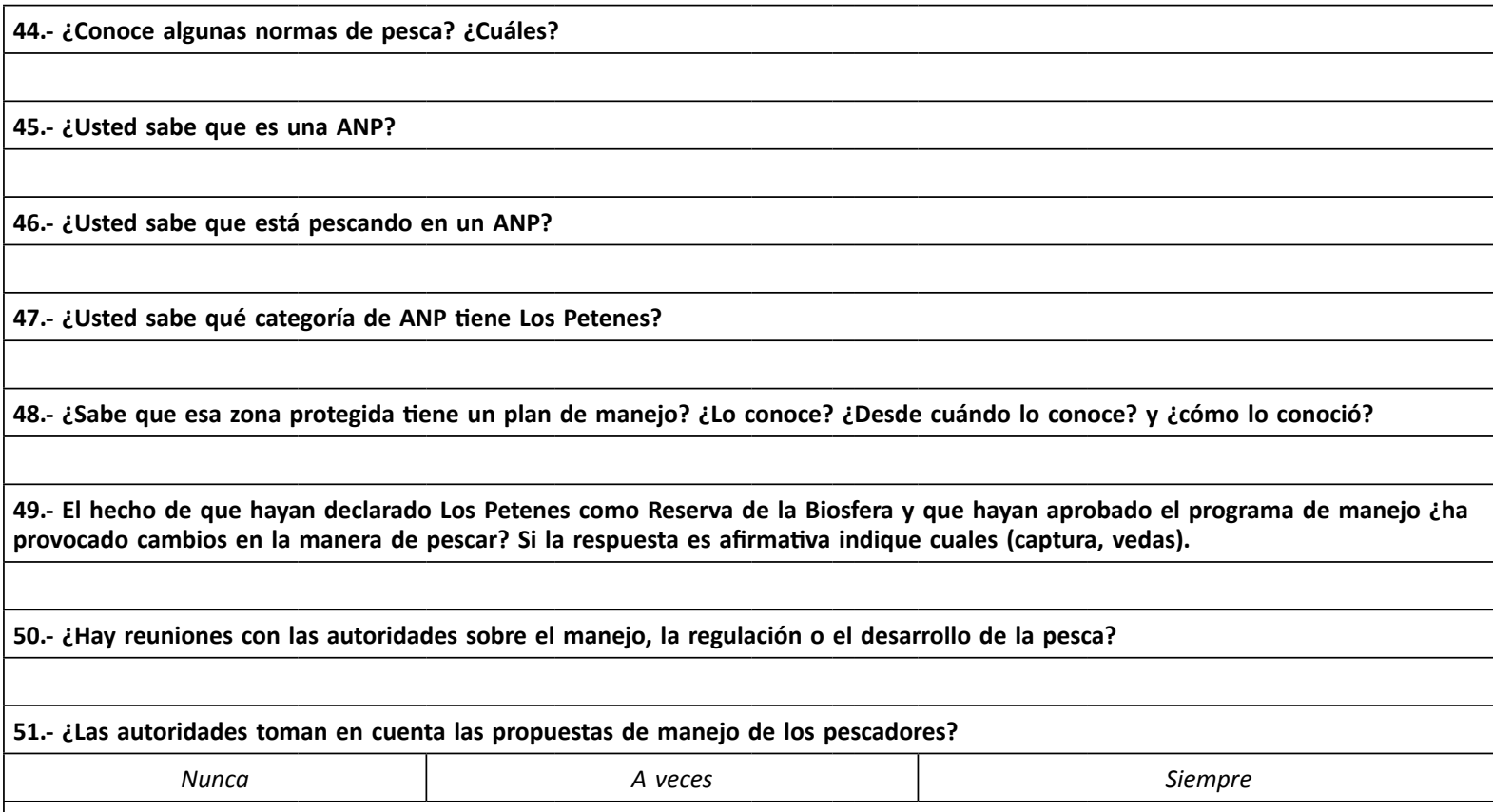

52.- El hecho de que hayan declarado Los Petenes como Reserva de la Biosfera ha influido en que haya menos pescadores? Si la respuesta es afirmativa indique la razón.

53.- ¿La introducción de PEMEX en Campeche ha afectado la pesca de alguna manera? Si la respuesta es afirmativa indique la razón

54.- ¿Qué tipo de repercusiones ha traído la declaración de Los Petenes como Reserva de la Biosfera a su pesca?

\begin{tabular}{|c|c|c|c|c|c|}
\hline Muy negativas & Negativa & Ningunas & Buenas & Muy buenas \\
\hline 55.- ¿Cómo evalúa su relación con las autoridades de la Reserva de la Biosfera? & Buena & Muy buena \\
\hline \multicolumn{2}{|c|}{ Muy mala } & Mala & Regular & Ba \\
\hline
\end{tabular}

56.- ¿Ha sido amonestado o le ha llamado la atención alguna autoridad u otra persona?

\begin{tabular}{|c|c|c|}
\hline \multicolumn{2}{|c|}{ Sí } & No \\
\hline Autoridad: & \multirow{3}{*}{ Tipo de amonestación } & Verbal \\
\cline { 1 - 1 } Otra persona: & & Infracción \\
\cline { 3 - 4 } & & Otro: \\
\hline
\end{tabular}

57.- En el caso de haberse producido ¿Quiere explicar el motivo?

58.- ¿Cree que la pesca comercial ribereña en la RBLP tiene futuro?

\begin{tabular}{|c|c}
\hline Sí & No \\
\hline
\end{tabular}

59.- ¿Cuáles son los principales problemas que tiene la pesca comercial ribereña aquí?

60.- ¿Ha pensado en algunas soluciones para resolver estos problemas? Si la respuesta es afirmativa indicar cuáles 


\section{LOCALIZACIÓN DE ÁREAS DE PESCA}

61.- Marque los principales lugares de pesca

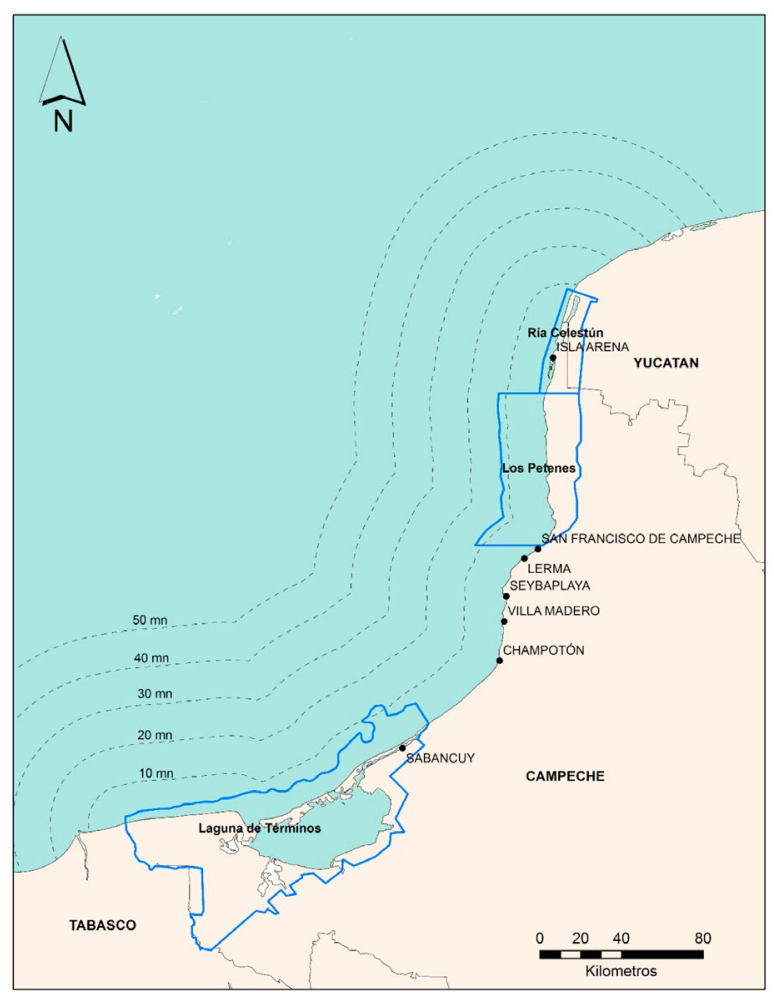

62.- Marque las principales zonas de desembarco

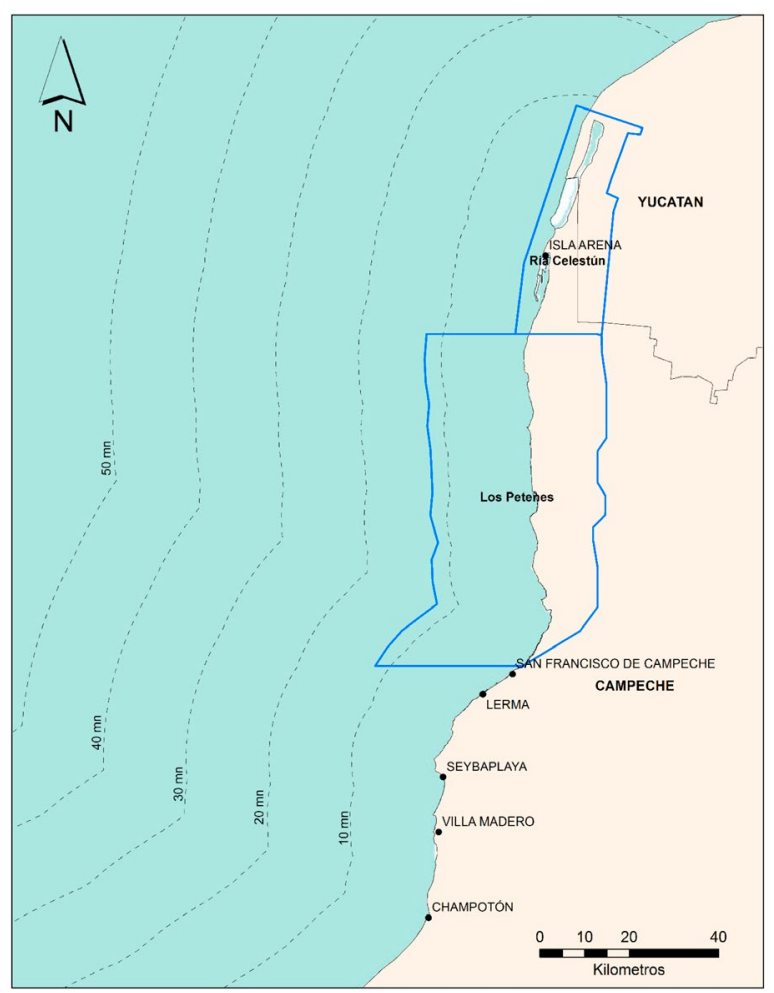

